\title{
Microfluidic-based virus detection methods for respiratory diseases
}

\author{
E. Alperay Tarim ${ }^{1} \cdot$ Betul Karakuzu $^{1} \cdot$ Cemre Oksuz $^{1} \cdot$ Oyku Sarigil $^{1} \cdot$ Melike Kizilkaya $^{1}$. \\ Mahmoud Khatib A. A. Al-Ruweidi ${ }^{2}$ Huseyin Cagatay Yalcin ${ }^{2} \cdot$ Engin Ozcivici $^{1}$ • H. Cumhur Tekin ${ }^{1,3}$ (I)
}

Received: 28 December 2020 / Accepted: 19 January 2021 / Published online: 25 March 2021

(C) The Author(s) 2021

\begin{abstract}
With the recent SARS-CoV-2 outbreak, the importance of rapid and direct detection of respiratory disease viruses has been well recognized. The detection of these viruses with novel technologies is vital in timely prevention and treatment strategies for epidemics and pandemics. Respiratory viruses can be detected from saliva, swab samples, nasal fluid, and blood, and collected samples can be analyzed by various techniques. Conventional methods for virus detection are based on techniques relying on cell culture, antigen-antibody interactions, and nucleic acids. However, these methods require trained personnel as well as expensive equipment. Microfluidic technologies, on the other hand, are one of the most accurate and specific methods to directly detect respiratory tract viruses. During viral infections, the production of detectable amounts of relevant antibodies takes a few days to weeks, hampering the aim of prevention. Alternatively, nucleic acid-based methods can directly detect the virus-specific RNA or DNA region, even before the immune response. There are numerous methods to detect respiratory viruses, but direct detection techniques have higher specificity and sensitivity than other techniques. This review aims to summarize the methods and technologies developed for microfluidic-based direct detection of viruses that cause respiratory infection using different detection techniques. Microfluidics enables the use of minimal sample volumes and thereby leading to a time, cost, and labor effective operation. Microfluidic-based detection technologies provide affordable, portable, rapid, and sensitive analysis of intact virus or virus genetic material, which is very important in pandemic and epidemic events to control outbreaks with an effective diagnosis.
\end{abstract}

Keywords Microfluidic $\cdot$ Respiratory disease $\cdot$ Viral pathogen $\cdot$ Virus Detection $\cdot$ Biosensors, $\cdot$ COVID-19

\section{Introduction}

Respiratory tract infections have been a great danger for children, adults, and elders for years. Influenza A and B, parainfluenza, adenovirus, respiratory syncytial virus, human metapneumovirus, human rhinoviruses, Enterovirus 71 , bocavirus, and coronavirus are examples that can cause respiratory tract infections [1]. According to the World Health Organization (WHO) estimations, 1.9 million children die each year due to acute respiratory infections [2].

E. Alperay Tarım, Betul Karakuzu and Cemre Oksuz contributed equally to this work.

H. Cumhur Tekin

cumhurtekin@iyte.edu.tr

1 Department of Bioengineering, Izmir Institute of Technology, Urla, Izmir, Turkey

2 Biomedical Research Center, Qatar University, Doha, Qatar

3 METU MEMS Center, Ankara, Turkey
Based on its prevalence, respiratory tract infections are the sixth leading cause of mortality [3]. The coronavirus variants previously appeared as SARS-CoV-1 and MERS$\mathrm{CoV}$, and later emerged in 2019 in China as SARS-CoV2 and spread worldwide within months [4]. Recent outbreaks of SARS-CoV-2 cause more than 1.5 million deaths as of 2020 December [5]. This virus can be transmitted both directly such as saliva and secretion droplets and indirectly from object surface [6]. Infected people show symptoms such as fever, cough, shortness of breath, fatigue, loss of taste or smell, headache, runny nose, and diarrhea [7]. According to evidence related to SARSCoV-2, symptoms appear after approximately 5.2 days and the virus can cause hemorrhagic and immunologic responses that can affect multiple organs [8]. Long-term consequences of SARS-CoV-2 including neuropathy and decreased lung capacity are still unknown, but it will be enlightened by ongoing studies $[9,10]$. It is difficult to distinguish SARS-CoV-2 and flu from each other because some symptoms are similar. Due to the high transmission rate of SARS-CoV-2 (R0: 1.4-5.5) and similar symptoms 
of SARS-CoV-2 with other respiratory viruses, early and specific diagnosis is required [11].

Microfluidic systems can be used in a wide range of areas in biotechnology such as detection, separation, and mixing, and therefore offer cutting-edge applications for the diagnosis and detection of diseases [12, 13]. Microfluidics including components such as pumps, actuators, and valves are miniature technologies that offer easy-to-use, efficient, and specific detection for biological agents [14, 15]. Moreover, microfluidic technologies allow the integration of smart solutions such as e-health, the Internet of Medical Things (IoMT), artificial intelligence, and machine learning for developing innovative healthcare technologies [16, 17]. Microfluidic technologies enable economic, fast, portable, and sensitive analysis opportunities, and offer versatility in development as the fabrication can be achieved with different material bases such as poly(dimethylsiloxane) (PDMS), poly(methyl methacrylate) (PMMA), polycarbonate, glass, paper, hydrogel, polytetrafluoroethylene (PTFE), thermoset materials, threedimensional (3D) printing materials, and silicon [12, 18-20]. Microfluidic systems can be used for real-time sensing and monitoring, can work with small sample and reagent volumes, can allow multiplexing, and can be assembled into multiple microfluidic components $[18,19]$. Therefore, those systems emerge as a great alternative to commercial detection and imaging systems.

The physical and chemical environment of the microfluidic systems can be precisely controlled, enabling a high-quality assessment that is required for viral biology research [21]. Translated to the clinic, early and accurate detection of viral diseases leads to early intervention, controlling the spread of disease and prompting clinical care by using microfluidic technologies [22, 23]. Microfluidic technology can offer superior capabilities for virus detection in terms of time, detection speed, and limits of detection [22]. Detection of the viruses can be conducted in either direct ways (i.e., an antigen, DNA/RNA are targeted via direct detection methods) or indirect ways (i.e., serologic tests that determine $\operatorname{IgM}$ and $\mathrm{IgG}$ antibodies in serum or plasma are used). Detection methods can further be improved by integrating them with artificial intelligence (AI) or internet-of-things (IOT) to perform point-of-care (POC) application during SARS-CoV-2 [24].

Considering the increase of virus-based epidemics/ pandemics and respiratory tract diseases due to these epidemics/pandemics, we aimed to compile current technologies that use microfluidic-based detection methods directly to the types of virus-related respiratory diseases. For this purpose, the types of viruses that cause respiratory diseases were given and conventional virus detection methods were explained. Moreover, the microfluidic-based direct detection methods used in the detection of these viruses in the last decade were explained in detail. The microfluidic-based direct virus detection systems (Fig. 1) are described based on the underlying detection methodology as optical, electrical, etc., and also commercial examples are also discussed. The importance of the use of microfluidics technologies in the detection of viruses that cause respiratory infections was emphasized. The difficulties encountered in virus detection were also explained. Hence, this review paper could be a handbook for researchers who will develop and use these microfluidic-based virus detection techniques.

\section{Respiratory Disease Viruses}

Influenza viruses infect almost one billion people as acute respiratory disease and cause deaths over 500,000 in humans every year according to the WHO's estimation [25]. Young children and elderly people who have chronic diseases are the most affected population subgroups [26]. Influenza viruses that are enveloped and have negative-strand RNA are categorized into three subtypes as influenza $\mathrm{A}, \mathrm{B}$, and $\mathrm{C}$ in humans [27]. Among them, influenza A and B are the most common types causing seasonal epidemics every year [28]. In the past, influenza A subtypes caused various pandemics. One of the deadliest influenza A pandemics was Spanish flu emerging in 1918. It is estimated that 500 million people were infected, and 40 million people died worldwide because of this pandemic [29, 30]. Asian flu (H2N2), Hongkong flu (H3N2), and Swine flu (H1N1) were the following influenza pandemics causing fewer mortalities [31]. On the other hand, the influenza B virus has not caused a pandemic before, however, it has caused local epidemic [32]. Symptoms such as fever, sore throat, headache, and nasal congestion are seen as indicators of influenza generally. The incubation time of the disease can change from 1 to 4 days. Rest and fluid intake are advised by physicians for healthy individuals for the treatment. Young children, elderly people, or people who have chronic health conditions may receive extra supportive medicine. There are available vaccines for the disease but, as virus strains mutate every year, vaccines are required to be updated yearly to remain effective in prevention [26].

Human adenoviruses (HAdVs), which are found in the Adenoviridae family, cause infections involving the respiratory tract, gastrointestinal tract, or conjunctiva, and pose a high danger to human health. HAdV is a non-enveloped and double-stranded DNA virus with 7 species and more than sixty serotypes [33]. Hemorrhagic cystitis, hepatitis, hemorrhagic colitis, pancreatitis, nephritis, fewer, or encephalitis are rare symptoms of HAdV infections. Adenovirus infections are more common in younger age groups due to humoral immunity deficiency. Besides, the severity of the disease, as well as its potential for transmission, is high in patients with impaired immunity. In closed or crowded environments, HAdV infections can reach epidemic dimensions, and their contagiousness increases [34]. HAdV, which has epidemic samples in 
Fig. 1 Overview of microfluidic methods used for detection of respiratory viruses. Various collected samples (genetic materials or direct respiratory virus particles in body fluids) can be detected using microfluidicbased detection systems that can contain antibodies, aptamers, magnetic beads, nanoparticles, or enzymes

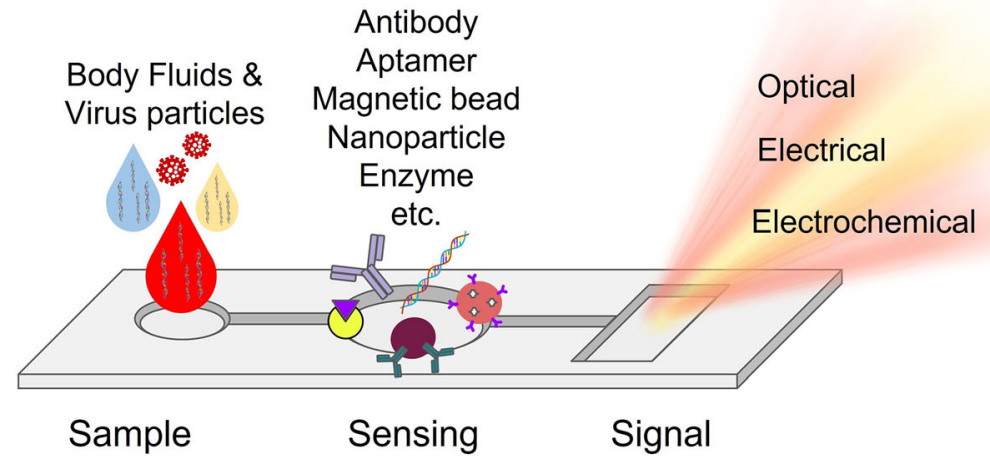

certain regions, is a very suitable virus to reach pandemic sizes [35-38].

Human bocavirus (HBoV) is a non-enveloped, singlestranded DNA virus that belongs to Parvoviridae and mostly affects children by causing upper and lower respiratory infections $[39,40]$. HBoV is the fourth most common pathogen found in respiratory tract diseases of children [41]. Other viruses have been found in $\mathrm{HBoV}$-positive children with a rate of $37-90 \%$ [42].

The human metapneumovirus (hMPV), which belongs to the Paramyxoviridae family, is an enveloped and negative single-stranded RNA virus. It can cause severe respiratory disease in individuals with a low immune system [43-47]. Fever, cough, shortness of breath, bronchiolitis, and pneumonia are common symptoms in patients infected with hMPV [44, 48-51]. Although its recent discovery has accelerated the development of drugs and vaccines that effectively affect hMPV, methods are yet to be developed for the detection and treatment of this infection [47, 49].

The human rhinoviruses (HRVs) grouped into 3 different types as HRV-A, HRV-B, and HRV-C are positive singlestranded RNA virus within the Picornaviridae family [52-54]. These viruses, which preserve their genomic material in the capsid, interact with the intercellular adhesion molecule 1 (ICAM-1) receptors on the surface of the host cells [55]. HRV, which is a non-enveloped virus, can be seen in a wide range of patients from infants to the elderly, including patients with suppressed immune systems $[52,56]$. Although HRV is known to be transmitted by the mucous fluid resembling a common cold, its infections can cause different respiratory diseases [57]. HRV, which brings on upper respiratory tract diseases, bronchiolitis, asthma, and chronic pneumonic diseases in the advanced stages of the infection, threatens human life because of fatalities [52, 58, 59].

Respiratory syncytial virus (RSV) is one of the enveloped, single-stranded, and negative-sense RNA viruses [60, 61]. It consists of two subtypes, types A and B, which are classified with their antigenic variability [62]. RSV is highly contagious and can infect people of all ages but predominantly observed among children and infants. It is one of the leading causes of illnesses such as bronchiolitis or pneumonia in young children $[60,61]$. According to WHO, in 2017, over 30 million RSVrelated infections in infants and children were estimated annually [63]. Also, elderly and immunocompromised people are reported as high-risk groups with significant morbidity and mortality [64-66]. RSV causes seasonal epidemics mostly beginning in the fall and peaking in the winter [60, 67]. In case of need, nasal/nasopharyngeal swabs or aspirations are mostly used to collect samples [68, 69]. Still, there is no effective vaccine against RSV; however, about 60 vaccine candidates are currently in different phase trials [63, 70].

Parainfluenza viruses (PIVs) are one of the enveloped single-stranded RNA viruses. They have 4 subtypes and are categorized in the Paramyoviridaie family. When infection occurs, viruses affect the upper and lower respiratory tract of infected people mainly. Symptoms start in the nose and then the virus can spread to lower airways in approximately 5 days. Parainfluenza viruses can infect any person worldwide and infection time can change according to seasons [71]. There is no vaccine or available antiviral treatment for these viruses, and only hygiene and sanitation practices are recommended [72].

Enterovirus 71 (EV71) is a member of the Picornaviridae family and is classified as a non-enveloped single-stranded RNA virus type. EV71 infects both children and infants but the infection is seen in children at a higher rate [73]. Infected children develop a disease called HFMD (hand, foot, and mouth disease) and China was the epicenter of the outbreak in 2012. General symptoms of the disease are fever and ulcers in the different areas of the body such as mouth and hands. Vaccines were developed in recent years for the prevention of the disease [74].

Coronaviruses (CoVs) are found in the Coronaviridae family and are classified into four groups as alpha, beta-, gamma-, and delta-coronaviruses $[75,76]$. Coronaviruses are singlestranded RNA viruses that affect the respiratory system. CoV-229E, CoV-NL63, CoV-OC43, and CoV-HKU1 are four strains of human coronaviruses that show cold-like symptoms. Contrarily, severe acute respiratory syndrome coronavirus (SARS-CoV), Middle East respiratory syndrome-related 
coronavirus (MERS-CoV), and SARS-CoV-2 cause fatal lower respiratory diseases [4]. In 2003, SARS-CoV outbreaks in Asia infected more than 8000. In 2012, MERS-CoV was first seen in Saudi Arabia and, infected people showed severe acute respiratory symptoms such as fever and cough [77]. In late 2019, SARS-CoV-2 first appeared in China and rapidly became a worldwide pandemic [78]. As of 2020 December, there were about 65 million confirmed cases and over 1.5 million deaths [5]. SARS-CoV-2 is a crown-like enveloped single-stranded RNA virus that belongs to beta-coronavirus [79]. The early diagnosis of SARS-CoV-2 is important to prevent disease spread and the treatment $[11,80]$.

\section{Conventional virus detection methods}

Many new methods have evolved or been invented to detect viruses. Medical professionals and researchers have faster, accurate, simple, and useful methods in the diagnosis, monitoring, and treatment of diseases caused by respiratory viruses. There are methods in which the findings are directly related to the virus such as nucleic acids, proteins, and virus particles. These methods are of great importance in virus detection by giving quantitative and/or qualitative results. Another method, indirect virus detection, is to detect the presence of the virus by investigating the metabolic changes (e.g., antibody amount) in the organism infected with the virus.

\subsection{Direct Detection}

\subsubsection{Polymerase Chain Reaction}

Polymerase chain reaction (PCR) is a rapid, sensitive, and specific in vitro molecular technique that allows rapid amplification of specific segments of DNA, in most cases specific genes of interest [81]. The technique requires five main components: DNA template which contains the segment of interest of DNA to be amplified; two primers to determine the start and the end regions of amplification; Taq polymerase that copies the DNA amplified region; nucleotides which are used for making the new DNA with the DNA polymerase; and buffers for optimum DNA polymerase chemical environment [82]. Three main steps of PCR have repeated over 20-35 cycles which are denaturing of DNA, annealing of primers, and extension of DNA [83]. As a result, 100 billion of similar genetic materials can be produced via PCR.

The most common types of PCR are real-time PCR [84], reverse-transcriptase PCR [85], and multiplex PCR [86]. For RNA viruses, detection of viral RNA requires the synthesis of cDNA and amplification via PCR while for DNA viruses, DNA is amplified directly. Currently, PCR is the gold standard for respiratory infections, including COVID-19 diagnosis by identification of SARS-CoV-2-specific RNAs.
Historically, PCR was used for the detection of several respiratory viruses. In 1998, Echavarria et al. introduced a new PCR method that amplifies the hexon gene to detect HAdV in urine in a fast and efficient manner [87]. The new assay was capable of detecting all 18 known stereotypes known at that time with optimized urine processing. In 2000, Xu et al. designed a PCR assay by using primers for fibers gene that in a single amplification reaction can differentiate HAdV from A to $\mathrm{F}$ types [88]. Besides, the assay could identify all 49 prototype strain species that were known at that time. In 2003, Gu et al. designed a multiplex PCR assay for several group of HAdV [89]. There are five primers that compose the assay and seven probes that can detect all adenovirus $\mathrm{A}, \mathrm{B}$, and $\mathrm{E}$ as well as 8 stereotypes from group D (stereotype G was not known at that time). In 2003, Heim et al. designed a quantitative PCR with primer and probe (TaqMan) sequences of the hexon gene for detection of HAdV [90]. Their designed model was capable of detecting all $51 \mathrm{HAdV}$ prototypes. This method gave more sensitivity compared to the convenient PCR. In 2004, Ebner et al. developed a two-reaction real-time PCR assay covering all HAdV A to F with high specificity and sensitivity [91]. In 2008, Damen et al. designed a real-time PCR assay that can detect all known HAdV at that time [92]. They chose from the hexon region as well as degenerate primers to cover all known serotypes. In 2019, Dong et al. developed a method for rapid detection of fowl adenovirus serotype 4 (FAdV-4) and FAdV-10 in chicken through a droplet digital PCR (ddPCR) assay [93]. The authors assessed the qualification of the assay to detect FAdV-4 contamination in Newcastle disease virus vaccines and compared it to quantitative real-time PCR (qPCR) and a conventional PCR assay. In 2020, Nebeluk and Foster [94] published a method for the evaluation of adenovirus type 5 transcriptional patterns using a SYBR green-based quantitative qPCR. They developed a qPCR assay for the majority of the HAdV5 genome that allows the quantification of transcriptional activity. Through computational modeling, they used panel specific adenovirus gene primers that are compatible under a single reaction condition [94, 95].

In 2006, Lu et al. developed two real-time TaqMan PCR that is sensitive and effective towards HBoV [96]. They mainly targeted HBoV NS1 and NP-1 genes. Developed assays detect up to 10 copies of recombinant DNA plasmid with a HBoV genome's partial region $\left(10^{1}\right.$ to $10^{8}$ copies $)$. In 2007 , Neske et al. developed another real-time PCR assay for the diagnosis of HBoV [97]. Their assay aimed to quantify the HBoV DNA and aimed to use it in the analysis of stool and serum samples for testing the presence of HBoV DNA. Their qualitative result corroborated with the conventional $\mathrm{HBoV}$ PCR. Their results were also important for confirming the presence of $\mathrm{HBoV}$ in stool. In 2008, Choi et al. described a novel method for the detection of $\mathrm{HBoV}$ based on real-time PCR assay [98]. They used the gene bank's library to design 
primers and probes. For target sites, they analyzed the following genes as they were applicable for TaqMan real-Time PCR.

Other than $\mathrm{HAdV}$ and $\mathrm{HBoV}$, major viral infections diagnosed with PCR are influenza, rhinovirus, syntactical virus, and enterovirus. In 1998, Echevarria et al. developed a method for the simultaneous detection of three serotypes of parainfluenza virus 1, 2, and 3 through RT-PCR multiplex assay [87]. The assay could detect and differentiate between the three types in a combined reaction. On conserved regions of the hemagglutinin-neuraminidase gene, a mixture of three pairs was used for primary amplification and yielding of amplicons of the same size. In 2004, Templeton et al. developed a method for detection of parainfluenza 1,2,3, and 4 as well as influenza A and influenza B viruses, and human RSV that uses molecular beacons to distinguish pathogens within a two-tube multiplex reaction [99]. In 1992, Claas et al. developed a method for influenza viruses $\mathrm{A}, \mathrm{B}$, and $\mathrm{C}$ by PCR [100]. In their method, they aimed to detect specifically for the RNA genome of each virus. Therefore, they chose three primers from the conserved regions of the genome coding for the non-structural proteins. In 2019, Henritizi et al. developed tetraplex RT-qPCR for influenza using primers and probes based on previously published assays [101]. In addition to that, more primers and probes for comprising full-length sequences were extracted from GenBank. The results proved that RT-qPCR is optimum, sensitive, and specific for the study of influence viruses and can be a powerful tool. In 2003, Mentel et al. developed a RT-PCR for syncytial virus as they used a primer/probe pair from the F gene [102]. This assay is specific for the detection of the virus and it has an advantage of the closed tube that eliminates contamination. In 2012, Anh Ha Do et al. developed a novel method for improved detection and quantification of syntactical virus [103]. Their method depends on quantitative RT-PCR that locks nucleic acid (LNA) probes to distinguish the groups A and B. In 1999, Andeweg et al. presented a method for the detection of rhinovirus using nested RT-PCR [104]. They designed primers and probes based on the most conserved regions to direct them there. In 2010, Do et al. developed a one-step real-time PCR for the detection of rhinoviruses [105]. They designed primers to amplify a target of picornavirus RNA with specific length and a TaqMan probes that were especially designed for specific detection of rhinovirus amplicon. This method allows sensitive detection of a variety of serotypes of rhinovirus with Applied Biosystems reagent-instrument platform. In 2008, Tan et al. presented a method for rapid detection of EV71 by real-time TaqMan RT-PCR [106]. They designed specific primers and probes based on theVP1 region of EV71. They proved that their method has $100 \%$ specificity to detect EV71 and sensitivity to 5 viral copies.

Regarding coronavirus studies, in 2004, Adachi et al. provided an RT-PCR assay that could detect SARS-CoV-1 and other members of coronaviruses (HCoV-OC43 and $\mathrm{HCoV}$ -
229E) with high efficiency and analytical sensitivity [107]. They developed a single-tube RT-PCR. In the method, the species could be identified through sequencing amplicon. Also, in 2004, Emery et al. developed a real RT-PCR that could directly detect SARS-CoV-1 in a fast manner [108]. The idea of the assay is based on several probes and primers located in different regions of the genome of the virus that are capable of distinguishing SARS-CoV-1 from other coronaviruses with a LOD smaller than 10 genomic copies per reaction. In 2004, Wu et al. developed an RT-nested PCR system for the detection of SARS-CoV-1 [109]. In their study, they presented 12 sets of nested PCR that cover the entire genome sequence of SARS-CoV-1. The nested primers were screened, and they showed efficient sensitivity to detect the virus in RNA isolated from Vero 6 cells. The specificity was found to be $100 \%$ while sensitivity was found to be $83 \%$. In 2012, Corman et al. presented two RT-PCR assays for SARS-CoV-1 [110]. They targeted the upstream region of E gene (upE) or the open reading frame (ORF) $1 b$, respectively. Their results indicated the sensitivity for the first one was 3.4 copies per reaction. They indicated the presence of no crossreactivity with other SARS-CoV-1 viruses nor other coronaviruses OC43, NL63, and 229E. In 2013, Lu et al. developed real-time reverse transcription-PCR (rRT-PCR) assays for the detection of MERS [111]. In their method, the developed assays target MERS-CoV nucleocapsid (N) gene and they compared these assays with the ones targeting upE in MERS. In their results, they found that all the assays provided a detection rate of smaller than 10 copies/reaction of quantified RNA transcripts and $1.3 \times 10^{-3} 50 \%$ tissue culture infective doses $\left(\mathrm{TCID}_{50}\right) / \mathrm{mL}$ of cell-cultured MERS-CoV.

In response to the current COVID-19 pandemic caused by SARS-CoV-2, in February 2020, Lu et al. developed a panel consisting of 3 RT-PCR assays to target the $\mathrm{N}$ gene in the virus [112]. They found that the limit of detection is 5 copies/reaction for all assays and $1 \times 10^{-1.5} 50 \%$ tissue culture infectious dose/ $\mathrm{mL}$ of cultured SARS-CoV-2. The assays were performed with serum, fecal specimens, nasopharyngeal, and oropharyngeal secretions spiked with the cultured virus. There was no detection for false-positive with other coronaviruses or respiratory pathogens. The US Food and Drug Administration (FDA) approved the panel for emergency use on February 4, 2020. In May 2020, Fuk-Woo Chan et al. developed and investigated the performance of three different RT-PCR assays that target RNAdependent RNA polymerase (RdRp)/helicase (Hel), spike, and nucleocapsid genes of SARS-CoV-2 [113]. The lowest limit of detection in vitro was the COVID-19-RdRp/Hel assay with 1.8 $\mathrm{TCID}_{50} / \mathrm{mL}$ with genomic RNA and 11.2 RNA copies/reaction with RNA transcripts. The assay did not show cross-reacting activities with other respiratory pathogens or other coronaviruses compared to RdRp-P2 assay which cross-reacted with SARS$\mathrm{CoV}-1$. The assays showed to be highly sensitive and can detect cases that were not detected by RdRp-P2 assay.

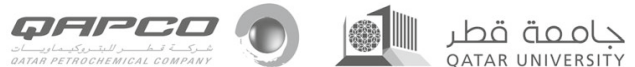
QATAR UNIVERSITY 


\subsubsection{Loop-mediated isothermal amplification}

A new milestone in the field of molecular biology was through the use of thermostable DNA polymer in PCR as primers [114]. Nevertheless, due to the limitations of PCR in general such as the need for complex instruments, other more practical methods were desired. Several isothermal techniques were developed at the beginning of the new century. Loopmediated isothermal amplification (LAMP) technique was developed and introduced for the first time by Tsugunori Notomi and his colleagues in 2000 [115]. The technique is unique as it is capable of amplifying DNA efficiently with a one-step reaction [116]. LAMP relies on two components: DNA polymerase, and four designed primers that are capable of the recognition of six distinct regions of the DNA [115] (i.e., two of these regions are outer primers and the others are inter primers) [ 117]. The process in LAMP consists of non-cyclic and cyclic steps. In the non-cyclic steps, artificial stem-loops are generated to be used in the cyclic steps. In the first cyclic step, the FIP binds to the sequence of targets to initiate polymerization. Consequently, F3 binds to the product displacing it with a stem-loop adding to the targeted sequence. Then, the DNA single-strand behaves as a template and the B3 binds to the product and displaces it with two adjoining artificial stemloops. The second cyclic step then takes a place with hybridization of FIP to the loop on the product. Initiation of DNA placement synthesis then takes place producing DNA with a new stem-loop structure and an additional target sequence. For further DNA synthesis, these structures will be used as templates in addition to internal primers. Inverted repeats of target sequence are obtained from different structures [118].

Upon its introduction, LAMP has been used for the identification of different respiratory viruses, including influenza, rhinovirus, enterovirus, and coronavirus. In 2003, Wakabayashi et al. presented a method for fast and sensitive diagnosis of adenoviral keratoconjunctivitis by LAMP [119]. In their method, they used an adenovirus (ad) type-specific primer for the gene of ad1, ad3, ad4, ad8, ad19, and ad37. In the study, the authors showed that the genotype of LAMP samples was identical to the PCR. In 2014, Sun et al. compared different DNA extraction methods, boiling, boiling in $1 \%$ Triton $\mathrm{X}-100$, and treating $0.02 \mathrm{M} \mathrm{NaOH}$ with DNAzol DNA extraction method [120]. Compared to the DNAZol method, the specificity of all three was $100 \%$ for adenovirus with the boiling method the most sensitive. The extracted template from supernatants of nasopharyngeal aspirates was further analyzed and showed higher sensitivity and specificity in LAMP assay compared with those for PCR. In 2006, Ito et al. developed RT-LAMP assays for the detection of influenza A virus $\mathrm{H} 1$ and $\mathrm{H} 3$ subtype strains and influenza $\mathrm{B}$ virus strains specifically [121]. For specificity, the strains were detected by strain-specific primers. For sensitivity, the virus was detected with a minimum concentration of $10 \mathrm{ffu} / \mathrm{m}$. The assay was shown to be more sensitive than immunochromatography and was found to be useful for diagnosing emerging influenza subtypes. In 2019, Nakauchi et al. developed two assays for the detection of rhinovirus by real-time fluorescent RT-LAMP [122]. The first assay was designed based on the $5^{\prime}$-untranslated regions (UTRs) of rhinovirus $\mathrm{A}$ and $\mathrm{B}$ and the second assay was designed based on the $5^{\prime}$-UTR of rhinovirus C. Efficiency of both assays was tested and compared with RT-PCR. Their sensitivity for rhinovirus A was $86.3 \%$ and for rhinovirus $\mathrm{C}$ was $77.3 \%$ on clinical specimens by the combined use of both assays. No crossreactions were reported. In 2013, Mahony et al. developed a rapid and sensitive multiplex LAMP assay for the detection of respiratory syncytial virus subgroups $\mathrm{A}$ and $\mathrm{B}$ (RSV A and B) [123]. In their study, primers were designed for RSV A matrix gene and RSV B polymerase gene. Their assay had a $100 \%$ sensitivity and specificity. Their total diagnosis time was 30 min. In 2014, Mu et al. developed RT-LAMP for 1-h detection for simultaneous detection of $A$ and $B$ groups of human syncytial virus [124]. They designed primers for groups A and B that specifically amplify the $\mathrm{N}$ and $\mathrm{L}$ genes of the virus. The limit of detection of new method was 281.17 and $1.58 \mathrm{TCID}_{50} / \mathrm{mL}$ for HRSV A and hRSV B, respectively. The test was useful for rapid detection. In 2019, Hu et al. developed an RT-LAMP method for simultaneous high detection of hRSV A and hRSV B group [125]. The primer designed for A group was on $M$ gene while the primer designed for B group was on M2-2 gene. For the amplification of hRSV RNA, real-time monitoring was achieved using SYTO9 as the fluorescent dye. In comparison of the new LAMP method with conventional RT-PCR, the positivity rate of RT-LAMP and RT-PCR was found as $67.8 \%$ and $55.6 \%$, respectively. In 2011, Wang et al. developed a single-step RTLAMP for the detection of enterovirus 71 [126]. The assay takes place in one tube and approximately $1.5 \mathrm{~h}$ at $65^{\circ} \mathrm{C}$. They found that the detection limit was about 10 copies. In addition, they found no cross-reactions with coxsackievirus A16, echovirus, HRV, or norovirus. Compared to conventional RT-PCR, this assay had greater sensitivity. In 2011, Yaqing et al. developed a one-step single-tube RT-LAMP for the detection of human EV71 [127]. The assay targeted the amplification of the VP1 gene in the presence of specific primers kept with DNA polymerase for $1 \mathrm{~h}$ at isothermal temperature conditions of $63^{\circ} \mathrm{C}$. The product was assessed through visual inspection and agarose gelelectrophoresis. After RNA extraction, compared to conventional RT-PCR, it was found that the assay was 10 -fold more sensitive. The assay was very specific and showed no cross-reactivity.

Regarding coronavirus studies, in 2003, Thai et al. presented a new assay called a one-step single-tube accelerated RTLAMP assay for SARS-CoV-1 detection for replicate gene [128]. Compared to conventional RT-PCR, their RT-LAMP was 100 -fold more sensitive with a 0.01 PFU detection limit. The sensitivity and specificity of RT-LAMP compared to RTPCR were 100 and $87 \%$, respectively. The amplification in RT-LAMP was carried out at $63{ }^{\circ} \mathrm{C}$ in a single tube under isothermal conditions. In 2017 , Hee Lee et al. developed a 
one-Pot RT-LAMP assay for detecting MERS-CoV [129]. In their method, they designed six LAMP primers using the sequence of nucleocapsid (N) gene: $100 \mathrm{U}$ M-MLVRTase and 4 Bst Polymerase. This means that the reaction has the ability to detect four viral copies in $60 \mathrm{~min}$. They used EvaGreen dye instead of SYBR green because it gives better signal readout properties in one-pot RT-LAMP reaction as well as it has excellent binding properties with DNA polymerase. In 2015, Bhadra et al. developed a RT Sequence-LAMP Assays for detection MERS-CoV [130]. Their method consists of isothermal amplification assays for MERS-CoV using open reading frame (ORF)1a and ORF1b genes and upstream of E gene (upE). In each assay, an incorporation of a single loop primer took place, and it affected the asymmetric amplification leading to an acceleration of the time-to-result of the OSD-RTLAMP assay. The assays have a detection ability of 0.02 to 0.2 plaque-forming units (PFU) (5 to $50 \mathrm{PFU} / \mathrm{mL}$ ) of MERS$\mathrm{CoV}$ between 30 and $50 \mathrm{~min}$. There was no cross-reaction. In 2018, Huang et al. provided a mixed technique that utilized rRT-LAMP, and vertical flow visualization strip (RT-LAMP$\mathrm{VF}$ ) for sole purpose of detection for $\mathrm{N}$ gene in MERS-CoV [131]. This assay could be performed in a constant temperature for about $30 \mathrm{~min}$ and a colorimetric result could be visible to the naked eyes within $5 \mathrm{~min}$. The technique could detect synthesized RNA transcript and MERS-CoV RNA at $2 \times 10^{1}$ copies $/ \mu \mathrm{L}$ and $1 \times 10^{1}$ copies $/ \mu \mathrm{L}$. There was no presence for cross-reactivities, and the method was highly specific.

In the early months of COVID-19 pandemics, Huang et al. applied RT-LAMP to achieve detection in $30 \mathrm{~min}$ for SARSCoV-2 detection [132]. In their assay, they designed four sets of LAMP primers and each set contained 6 primers to target the viral RNA of the virus in the $1 \mathrm{ab}, \mathrm{S}$ gene, and $\mathrm{N}$ gene regions. They produced a colorimetric response that is capable of nakedeye viral RNA detection. The reaction is a one-step process that does not require RNA extraction. The sensitivity was as high as 80 copies per milliliter of viral RNA. The results were in agreement with conventional RT-qPCR. Park et al. developed an RTLAMP assay for genomic RNA of SARS-CoV-2 [133]. Their assay could detect 100 copies per milliliter of SARS-CoV-2 RNA. There were no cross reactions with other respiratory pathogens nor coronaviruses. The assay adapts a colorimetric detection for high throughput. Hu et al. developed a novel RT-LAMP assay for SARS-CoV-2 and compared them to RT-qPCR [134]. They found that the RT-LAMP had $88.89 \%$ sensitivity and $99.00 \%$ specificity. Compared to conventional RT-qPCR with $81.48 \%$, they had an improved sensitivity of $88.89 \%$. Furthermore, no cross reactions were detected with other respiratory pathogens or coronaviruses.

\subsubsection{Microarray}

Microarray is another fascinating direct molecular technique that was established in 1990 by Patrick Brown and his team
[135]. A spot or feature in a microarray is the area where a specific probe is located. In the solid support, the probes are immobilized and the targets are applied as a solution onto the array for hybridization after fluorescent labeling [135, 136]. The DNA microarray possesses the size of a fingernail and it has at least 96 wells, each of them containing thousands of oligonucleotides or probes that are arranged in a grid manner [136-138]. There are two types of microarrays: cDNA (made by using robotic pins to print double-stranded cDNA on a solid support) and oligonucleotide (made by using photolithography to synthesize specific oligonucleotides in a specific alignment on a solid surface) [136, 139]. Hybridization can take place after the labeled cDNA is applied to microarray. Following the slide wash, it is expected that nonspecific hybridization is removed, and it is then read in a laser scanner that has the ability to differentiate between $\mathrm{Cy} 3$ and $\mathrm{Cy} 5$ signals allowing the production of separate 6-bit TIFF image for each channel due to the fluorescence intensity collected. cDNA pools that are reverse transcribed from mRNA samples can be distinguished with $\mathrm{Cy} 3$ and $\mathrm{Cy} 5$ fluorescent dyes. Quantification of fluorescent intensity is corresponding to gene expression in a sample. Since its discovery, it has been applied for efficient, specific, and sensitive amplification of both DNA and RNA from a variety of organisms and biological compartments [116]. A typical microarray consists of pieces of DNA that range from 20 to 5000 base pairs embedded into a designated area on a solid support. Furthermore, protein microarrays can also be used for the detection of protein-based biomarkers for diagnostic test [140, 141]. In these arrays, antibodies are extensively used as probes [142-144]. Adaptation of microarray to respiratory virus detection is fairly new. In 2003, Shih et al. developed a microchip for detection of enterovirus. In their approach, the amplified DNA was hybridized with oligonucleotide immobilized on a microchip [145]. For probes, two oligonucleotides were used: 5'-noncoding region (5'-NCR) sequence of the panenterovirus and the enterovirus 71-specific sequence of VP2 region. The specificity was found to be $90.0 \%$ while sensitivity was $89.6 \%$. The microchip array for enterovirus 71 could detect the amplicon of viral RNA as 1-10 virions in the specimen. In 2007, Quan et al. established and validated method for a sensitive microarray system for the detection of influenza viruses [146]. They were able to accurately characterize twenty one respiratory viruses. In 2007, López-Campos et al. developed a microarray assay for the detection of adenovirus [147]. They utilized amplicon retrieval software and positive controls as reference strains serotypes 1, 2, 3, 4, 5, 7, 14, and 21. Other strains were used for control of specificity. To assess sensitivity and specificity, additional controls of cloned amplified adenovirus type 1 , influenza virus (A, B, C), and respiratory syncytial virus (RSV A and B) were used. They successfully managed to develop an oligonucleotide microarray that could identify and detect adenovirus serotypes that are 
linked with respiratory infections accurately and efficiently. In 2018, Nybond et al. developed a microarray system composed of isothermal amplification of viral DNA with a paper-based vertical flow microarray (VFM) using functionalized gold nanoparticles (AuNPs) for colorimetric detection of amplicons [148]. They tested an in-house-designed probe and an adenoviral probe to validate microarray detection using synthetic target DNA down to $50 \mathrm{nM}$. In a recombinase polymerase amplification, the primers were proven to function using the synthetic template and viral DNA. The authors demonstrated the detection of adenovirus with four adenoviral species using the paper-based VFM. The assay could detect intra- and inter-assay CV\% of $\leq 9 \%$ and $\leq 13 \%$ from $1 \mathrm{ng}$ of starting material.

In 2004, Long et al. developed a universal microarray that integrates RT-PCR and ligase detection reaction (LDR) for the detection of SARS-CoV-1 [149]. For creating the universal microarray, the zip code attached to a side remaining constant and their complementary cZip codes were used for tagging the target sequence. The 5'end "cZip Codes" directs the product of LDR to specific codes linked covalently to a slide. In 2014, Guo et al. developed a microarray for the detection and genotyping of SARS-CoV based on a single-nucleotide polymorphism (SNP) target [150]. PCR was used for the hybridization of the product amplified from cDNA synthesis from different strains of SARS-CoV. The authors were able to detect 24 SNPs and determine their strain types. The hybridization was detected and genotyped with $100 \%$ accuracy using the microarray.

\subsubsection{ELISA}

Enzyme-linked immunosorbent assay (ELISA) is a molecular detection method that is based on the enzyme-labeled immunoassay [151]. One of the works that paved the way for the discovery of the method is the work of Aarameas that demonstrated the successfulness of the coupling of antigenantibody through the use of several enzymes [152, 153]. Two scientists named van Weemen and Schuurs described it independently as well in the same year in their paper entitled "Immunoassay using antigen-enzyme conjugates" [154]. In their work, they conjugated the antigens from human chorionic gonadotropin (HCG) to the enzyme horseradish peroxidase (HRP) and they used purified conjugates for "enzymeimmunoassay" of antibody and antigen. In general, an ELISA system takes advantage of enzymes that are attached to one reactant in the immunoassay followed by the addition of a proper substrate or chromogen that allows a colorimetric response to take place. The most common ELISA type is the solid-phase heterogeneous ELISA. For solid-phase heterogeneous ELISA, there are four main types: direct ELISA, indirect ELISA, sandwich ELISA, and competitive ELISA. Through the washing step, flooding and emptying the well using buffered solution ensures for successful separation of bound (reacted) from unbound (unreacted) reagents in the ELISA. Finally, the color development system allows results to be read and obtained through a spectrophotometer [155].

In 1979, Hamron et al. developed a solid-phase ELISA antihexon serum which was used for the detection of adenovirus antigen in cells [156]. Their results showed that in HEp2 cell cultures, with $10(2.5) \mathrm{TCID}_{50}$, antigens could be inoculated and 10 (1.5) TCID $_{50}$ after 2 and 4 days of incubation. Following 2 days of incubation, ELISA positive rate was $62 \%$ and no cytopathic effect was observed. After 4 days, ELISA positive rate was $76 \%$ and the cytopathic effect was $47 \%$. The immunofluorescent method and ELISA were nearly identical in results. In 1989, Al-Nakeb et al. developed a novel ELISA from nasal washings for direct detection of rhinovirus [157]. The new ELISA detected infection in volunteers indicating infection in a higher proportion of asymptomatic volunteers than the symptomatic ones. In 2014, Zhan et al. developed an assay for the detection of syncytial virus [158]. In their method, gold nanoparticles were used for the detection of the virus as carriers of the signaling antibody anti-RSV-HRP to achieve amplification of the signal. The advantage of this assay compared to conventional assay for the same virus was that it achieved a shorter time and higher sensitivity between 0.5 and $50 \mathrm{pg} / \mathrm{mL}$. In 2016, Leirs et al. developed a digital ELISA for detecting influenza A [159]. Seven commercial antibodies were selected to target influenza's nucleoproteins. There were two different platforms in that study: ELISA and surface plasmon resonance system. The antibodies behaved differently in each platform but overall they achieved good reactivity in both.

Regarding coronavirus work, in 2004, Lau et al. developed an ELISA for detecting SARS-CoV-1 nucleocapsid protein [160]. They utilized hyperimmune polyclonal nucleocapsidspecific antibodies and SARS-CoV-1 nucleocapsid protein with His6-tag. It was aimed to detect nucleocapsid protein of the virus in nasopharyngeal aspirate, urine, and fecal samples of infected patients that were collected between 2 days and 33 after confirmation of the infection. The specificity in hospitalized patients without SARS for nasopharyngeal aspirate was $96.7 \%$, urine is $99 \%$, and the fecal specimen was $96 \%$. As for SARS patients, assay detection was 34 (52\%) of nasopharyngeal aspirate samples, $5(5 \%)$ of urine samples, and $36(55 \%)$ of fecal samples. For SARS-CoV-2 detection, in October 2020, Schöler et al. developed a novel In-Cell ELISA (icELISA) assay for automated detection in $48 \mathrm{~h}$ [161]. They employed this approach suitable for direct antigen source for quantitative icELISA from SARS-CoV-2-infected cells. The specific signal of SARS-CoV-2 reduced depending on antiviral interferons and human sera containing virus-neutralizing antibodies (NAbs). Upon the application of increasing infectious doses, the icELISA-based neutralization test (icNT) was superior to plaque reduction neutralization tests (PRNTs) in 
the differentiation of convalescent sera with high sensitivity from others. Furthermore, they found that icNT is specific, in differentiating between SARS-CoV-2-specific NAbs and those triggered from other coronaviruses.

\subsubsection{Aptamer-based detection}

Aptamers are defined as artificial nucleic acids composed of single-stranded DNA or RNA, but can also be defined as a combination of unnatural nucleotides that act similarly to ligands that coordinate 3D folding of these proteins [162]. Aptamers are classified by loops, hairpins, pseudoknots, bulges, triplexes, and/or quadruplexes [163]. Aptamers can be useful in several applications such as generations of enzyme inhibitors, analysis of nucleic acid recognition, analysis of hormones and toxins, detection for the presence of target molecules, and generation of lead compounds in medicinal chemistry [163]. They can be described as relatively new technology and they have not been applied to many practices. Nevertheless, a few interesting innovations have been explored.

In 2008, through the use of exponential enrichment (SELEX) for H5N1 influenza virus, the selective evolution of ligands that screen DNA aptamers targeting recombinant HA1 proteins was utilized by Cheng et al. [164]. Eleven rounds of selection were performed and 10 aptamers were found with a strong binding to HA1 protein and an inhibitory impact to the H5N1 virus in hemagglutinin and MTT assays. In 2013, Wang et al. presented aptamers for the H5N1 virus based on SELEX and surface plasmon resonance (SPR) [165]. They selected aptamers after 13 rounds. They showed a strong affinity in terms of binding between HA and the chosen aptamer. They showed negligible cross-reactivity with other non-targets such as H5N2, H5N3, H5N9, H9N2, and H7N2. The aptamer showed promised selectivity towards H5N1. In 2013, an aptamer was developed by Shiratori et al. for multiplex influenza A virus subtypes that can bind to the HA1 protein using SELEX [166]. Besides, they developed a sandwich detection method based on aptamer to employ new determined aptamers. The developed enzyme-linked aptamer assay system was able to detect influenza A subtypes that were $\mathrm{H} 5 \mathrm{~N} 1, \mathrm{H} 1 \mathrm{~N} 1$, and $\mathrm{H} 3 \mathrm{~N} 2$ with equal sensitivity. In 2006, Gopinath et al. improved an aptamer-based method for sensing of influenza virus B [167]. In their method, they isolated RNA aptamer through an in vitro method and this aptamer was found to be efficiently bound to the HA of influenza $\mathrm{B}$ and involved $5 \mathrm{mM}$ of $\mathrm{MgCl}_{2}$ ion for its identification. In their findings, the aptamers can differentiate between influenza A and B. In 2014, Lai et al. developed an integrated microfluidic SELEX system to determine aptamers for influenza A/H1N1 (InfA/H1N1) virus in an automated mode [168]. In magnetic bead assay, the selected aptamer demonstrated high specificity and sensitivity detection towards InfA/
H1N1 virus, even in biological samples such as throat swabs. Besides, 20 aptamers showed outstanding affinity for InfA/H1N1. In 2017, Percze et al. provided a method that relied on the use of aptamers for sensing of syntactical viruses [169]. In their method, the SELEX protocol was followed to select aptamers. The aptamers were generated through a single molecule as the target of selection. The aptamers showed high selectivity towards syntactical viruses.

In July 2020, Zhang et al. reported the first DNA aptamer for targeting nucleocapsid protein of SARS-CoV-2 [170]. They were able to obtain four DNA sequences with an affinity of down to $5 \mathrm{nM}$ after five rounds of selection. The best binding towards the protein was with $0.49 \mathrm{nM} \mathrm{Kd}$ value. The four aptamers could bind successively to the protein in what they believe that it is a sandwich-structured interaction. The protein at the tens of pM level was successfully detected using ELISA and immunochromatographic strips. In October 2020, Liu et al. described a sensor for COVID-19 diagnosis using aptamers [171]. In the sensor, two aptamers could probe to the identical protein target and pull the ligation DNA field, thus initiating ligation-confirmed qPCR amplification. In their method, they were able to detect serum nucleocapsid quantitatively through the conversion of protein recognition into a detectable qPCR signal. The system was utilized and became a detection platform for special interactions between Spike S1 and the ACE2 receptor.

\subsection{Indirect Detection}

Although direct virus detection based on specific antigen or nucleic acid is preferable, there is also an indirect detection methodology based on the assessment of antibodies generated by the patient as a reaction to infection. This serological detection technique is widely used in research and clinics; however, it has disadvantages compared to direct detection, such as low accuracy and low specificity [172].

Immunoglobulin $\mathrm{M}$ (IgM) and immunoglobulin $\mathrm{G}(\mathrm{IgG})$ are antibodies created by the human body after infection [173]. Serum levels of both antibodies are indicators for infections. While IgM antibody is more related to the early stage of the infection, IgG antibody is used as an indicator of the middle or late period of the infection. So, combinations of these two antibodies are used for sensing of viral infections or determination of stages of the infection [173]. When the literature examples are examined related to respiratory virus detection through indirect methods, SARS-CoV-2 diagnosis was made by using a combination of IgM and IgG antibody detection [173]. Method used for the experiments was chemiluminescence immunoassay and experiments were carried out successfully for patients. According to results, assessment of IgM and IgG antibody combination showed better sensitivity and that would be a method to detect SARS-CoV-2. As a different example, detection of SARS-CoV-2 was aimed by using IgM 
and IgG antibodies and levels of antibodies were determined through chemiluminescence immunoassay [174]. So, this method was offered for diagnosis of COVID-19 disease. In another work, investigation of the potential of rapid IgG/IgM test by lateral flow assay (LFA) was conducted for SARSCoV-2 and compared with ELISA results [175]. Two main results of the study were that a combination of IgG and IgM antibodies did not increase specificity of the detection potential and that only IgG antibody detection without IgM antibody by LFA is more specific than by ELISA. Enzyme immunoassays were used to detect parainfluenza IgG and IgM antibodies [176]. When the levels of antibodies were measured quantitatively, it was shown that IgG antibodies reached more numerical value as percentage in patients infected by parainfluenza viruses.

Roggendorf et al. developed an ELISA assay by subjecting antibodies to hexone antigen of adenovirus through antigen-coated microtiter plate and peroxidasecoupled anti-human IgG followed by the addition of orthophenylenediamine and measuring the absorbance [177]. The authors discovered that the ELISA was 100-fold more sensitive than complement fixation. Barclay and Al-Nakib developed an ELISA for sensing of specific antibodies of rhinovirus in human sera and nasal secretions [178]. Rabbit anti-rhinovirus hyperimmune serum was used as the capture antibody via ELISA method. This ELISA system was proven to sensitively detect the rhinovirus-specific antibody for $\operatorname{IgG}$ and IgA immunoglobulins in serum. Wang et al. improved a detection method for EV71 through ELISA [179]. In their method, they relied on enterovirus 71IgM-capture ELISA. The sensitivity and specificity of the assay were found as 97.7 and $93.3 \%$, respectively. MacMullan et al. published a method for SARS-CoV-2 detection in saliva through ELISA [180]. In their method, commercially available Gold Standard Diagnostics (GSD) and EuroImmun (EI) kits were used to detect nucleocapsid protein $(\mathrm{N})$ and spike protein $(\mathrm{S})$, which are SARS-CoV-2 structural proteins to efficiently detect $\operatorname{IgA}$ and $\mathrm{IgG}$ antibodies. Both $\mathrm{IgG}$ and $\operatorname{IgA}$ kits from GSD and IgG kit from EI were found as $100 \%$ specific, while IgA kit from the EI was found as $92 \%$ specific for serum samples. They chose the EI IgG kit for the optimization and saliva experiment. Two different methods were compared for saliva collection: using oral fluid specimen collection device from OraSure Technologies and a mouthwash prepared from an inhouse formulation using a subset of saliva samples. They found that the mouthwash yielded $100 \%$ sensitivity while the OraSure Collection Device yielded only $87 \%$ sensitivity. Furthermore, they managed to achieve a total $84.2 \%$ sensitivity and $100 \%$ specificity in a set of 149 clinical samples.
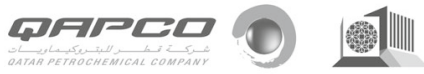

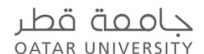

\section{Virus detection in microfluidic devices}

\subsection{Optical detection techniques}

In this section, we reviewed recent studies that make original and innovative contributions to the literature about optical detection of respiratory virus including absorbance, surface plasmon resonance, localized surface plasmon resonance, fluorescence, naked-eye or colorimetric, and others in microfluidic devices. Methods were explained by referring to their contributions for the virus detection, used labels, limit of detection (LOD), and detection methodology in detail.

\subsubsection{Absorbance}

Absorption spectroscopy technique is an important factor in molecule detection and laboratory diagnostics. In this technique, the attenuation or intensification of the wavelength of the light is measured with a spectrophotometer. The spectrum obtained in the spectrophotometer is measured as absorption differences that help define the concentration or composition of the molecule or sample to be determined [181, 182].

With the evanescent wave absorbance technique, the light-emitting diode (LED) is connected to the optical fibers and measured with a suitable photodetector at the output. In this method, a local change in the refractive index affects the absorbance with an analyte-originator, and the change in absorbance is measured (Fig. 2a). This method has been used for molecular detection such as immune sensitive biosensing, detection of unicellular organisms such as bacteria [183], and analysis of heavy metals [184], proteins [185], antibiotics [186], and biological biomarkers, and it has also been shown that it can be used for direct and indirect detection of the SARS-CoV-2 virus [187]. Using the plasmonic fiber-optic absorbance biosensor technique, direct detection of SARS-CoV-2 virus particles without washing was achieved by measuring the loss of optical power (absorbance/ intensity change) in light [188]. In the designed method, binding of SARSCoV-2 or free N-protein to capture antibodies attached to the surface provides a decrease in light intensity. The most important feature of the method is that the results can be obtained in around $15 \mathrm{~min}$ without performing sample preparation. Moreover, the influenza virus can be detected with grayscale images using an absorbance-based method [189]. It enables the detection of influenza virus strains by coating of polydopamine/protein $\mathrm{G}$ mixture and immobilization of an antibody against pH1N1. Absorbance-based methods can be used for direct detection of viral nucleic acids, such as influenza A, SARS-CoV-1/2, using LAMP with integrated optical fibers into a chip [190]. 
Fig. 2 Illustrations of opticalbased microfluidic platforms for detection of respiratory viruses or their products. a Absorbancebased detection technique, $\mathbf{b}$

Micropore array used for fluorescent detection. c Colorimetric detection in a paper-based microfluidic platform using RTLAMP (a)

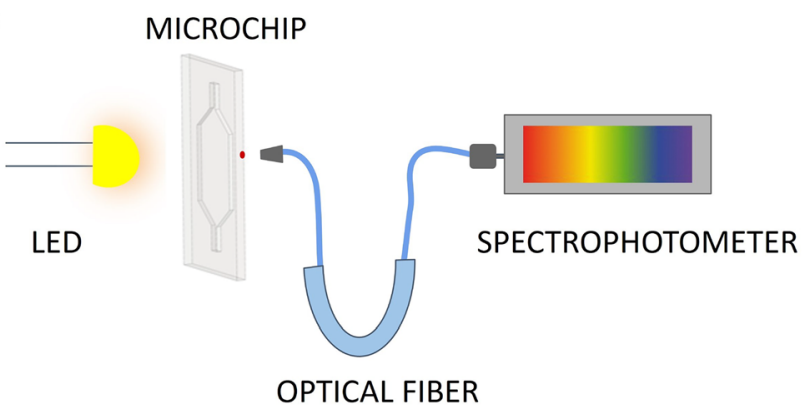

(b)

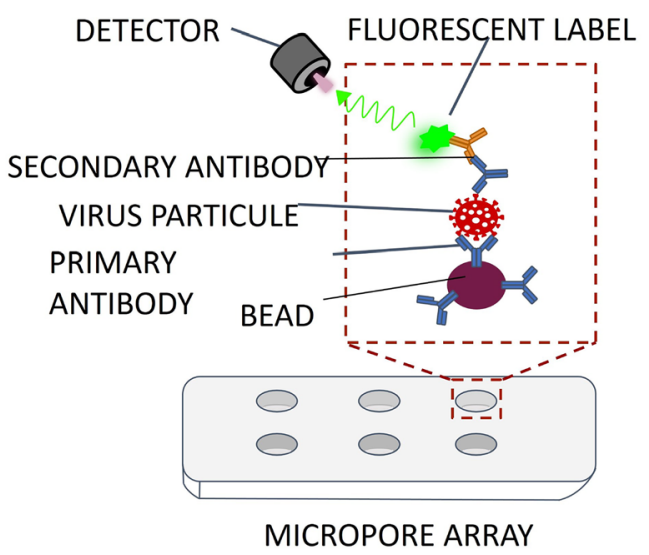

(c)

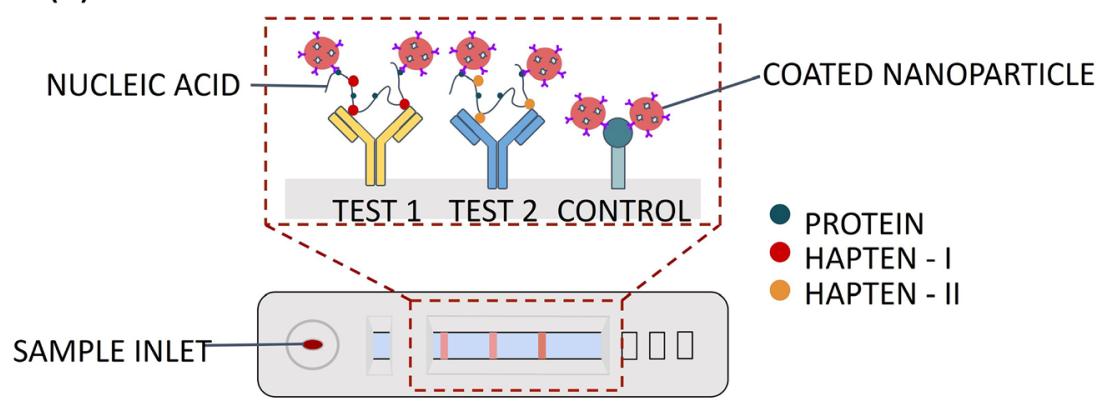

\subsubsection{Surface plasmon resonance}

SPR sensors are used for highly sensitive and real-time detection. SPR is defined as the condition of surface plasmon as a result of the interaction with a photon on a metal-dielectric interface [191, 192]. SPR sensors make analyte detection by measuring refractive index changes of the surface. They have wide range applications in environmental and medical diagnostics based on detection of target analytes such as proteins, nucleic acids, and viruses. Properties of SPR sensors providing labelfree and sensitive detection make them essential tools [191-195]. Localized surface plasmon resonance (LSPR) sensors developed by nanostructured substrates are improved versions of SPR sensors. Usage of nanostructures in LSPR sensors provide reliable, faster, more responsive and sensitive detection of analytes when compared to SPR sensors [191, 196, 197].
SPR biosensor was used for detection of 9 respiratory viruses which are influenza (A and B), respiratory syncytial virus (RSV), parainfluenza virus (1-3), adenovirus, and severe acute SARS within $30 \mathrm{~min}$ [74, 198]. Nine oligonucleotides specific to respiratory viruses were immobilized on gold SPR chip. Labeling of oligonucleotides was made by synthetic amino $\left(\mathrm{NH}_{2}\right)$ groups. SPR biosensor technology was used for avian influenza A (H5N1) antibody biomarker detection with an assay time of $60 \mathrm{~min}$ [199]. SPR sensor increased the detection limit (193.3 $\mathrm{ng} \mathrm{mL}^{-1}$ ), which is more than 3-fold compared to available commercial systems for H5N1 antibody biomarker. A label-free SPR method was used for human EV71 detection [200]. This miniaturized and portable platform was built by attachment of color tunable organic light-emitting diode to prism. As a biomarker, a major capsid protein of EV71 (VP1) was selected. Detection limit of this highly sensitive SPR-based 
sensor was about $4.8 \mathrm{pg} / \mathrm{mL}$. In another study, plasmonic biosensor combined with LSPR technology was used for SARSCoV-2 detection [32, 201]. Combination of gold nanoislands (AuNIs) and complementary DNA receptors was made for SARS-CoV-2 detection through hybridization. On the AuNIs chip, the thermoplasmonic heat was generated to enhance sensing abilities. Developed label-free LSPR biosensor showed high sensitivity and low detection limit (0.22 pM) for SARS-CoV-2 detection from multigene mixture. In a different study, a magnetic and reusable SPR sensor chip was designed and used in conventional SPR systems for testing detection of H1N1 nucleoprotein detection [202]. In the sensing step, ferromagnetic patterns were selected to trap magnetic particles on SPR surface. Immobilization of antibodies was also made by EDC-NHS coupling method onto magnetic particles. After sensing step, magnetic particles held by ferromagnetic patterns separated from the chip by using external magnetic fields to make the SPR sensor chip reusable with new magnetic particles.

\subsubsection{Fluorescence}

Fluorescence detection method is commonly used in nucleic acid detection by using labeled fluorescent reporters to detect targets. Currently, $80 \%$ of the SARS-CoV-2 detection methods are performed by fluorescent signal detection of PCR products [11].

Electrical field combined microfluidic CRISPR-based detection provides $30 \mathrm{~min}$ assay time for the SARS-CoV-2 detection from the raw sample [203]. In this system, CRISPRCas 12 enzyme and synthetic guide RNA (gRNA) was complexed and this complex specifically bound to target DNA. Viral $\mathrm{N}$ and $\mathrm{E}$ genes and human RNase $\mathrm{P}$ genes were targeted. Then, fluorophore-quencher-labeled ssDNA reporter probes was cleaved by this complex and fluorescent signal was observed. Electrical field was used to control and accelerate the CRISPR assay. Isotachophoresis (ITP) can separate charged analytes based on their ionic mobility by applying an electrical field. Thus, the extraction and automated purification of target was achieved. LOD of this system was found as 10 copies $/ \mu \mathrm{L}$ with a consumption of less than $0.2 \mu \mathrm{L}$ reagent. In this platform, the electrical field addressed the challenges of conventional CRISPR applications. This study is really advantageous due to no requirement for the separate nucleic acid extraction and on-chip extraction only takes $5 \mathrm{~min}$. Simultaneous detection of influenza viruses (H1N1, H3N2, H9N2) was achieved by nucleic acid hybridization with controllable micromagnetic field to create a magnetic reaction area for cDNA recognition by capturing magnetic nanoparticles modified with capture probe DNAs (CP-DNAs) on a microfluidic chip platform [204]. Quantum dot (QD)-assisted fluorescence signal measurement was achieved with LOD of $0.21 \mathrm{nM}$ for $\mathrm{H} 1 \mathrm{~N} 1,0.16 \mathrm{nM}$ for $\mathrm{H} 3 \mathrm{~N} 2$, and $0.12 \mathrm{nM}$ for H9N2. In this system, the sample and reagent consumptions were only $3 \mu \mathrm{L}$.
A developed microfluidic system allowed detection of multiple influenza viruses, such as influenza A H1N1, H3N2, and influenza B, in 20 min [205]. In this study, a single universal aptamer was used due to its ability to recognize influenza viruses and also ability to change conformation depending on the different conditions, so different influenza viruses could be identified. After the mixing of universal aptamercoated magnetic beads and viral sample, fluorescent-labeled single universal aptamer was added to the reaction chamber. LOD of this system was found to be 3.2 hemagglutinating units (HAUs), significantly lower compared to conventional hemagglutinin assays that have a typical LOD of 32 HAU. Immunomagnetic bead-based microfluidic system was designed for the detection of influenza A virus [206]. Viral particles bound to immunomagnetic beads and optical signals of magnetic complexes were analyzed. Integrated suction-type microfluidic control module, incubation module, and optical detection module performed sample incubation, purification, and optical detection automatically. Influenza A viral particles in the sample were captured by mouse anti-influenza nucleoprotein (NP) monoclonal antibody ( $\mathrm{mAb}$ )-conjugated magnetic beads. Then, another mouse anti-influenza NP mAb labeled with R-phycoerythrin (PE) was incubated on magnetic beads. Finally, fluorescent signals were detected by an integrated optical detection module (Fig. 2b). LOD was found as $5 \times 10^{-4}$ HAU which is much better than conventional benchtop systems. Another study was performed for the multiple virus detection using fluorescence magnetic multifunctional nanospheres [207]. Fluorescent magnetic multifunctional nanospheres were prepared by combining magnetic nanoparticles and quantum dots with different emission wavelengths. Green, yellow, and red fluorescent magnetic nanospheres (GMNs, YMNs, RMNs) were conjugated with antibodies against H9N2, H1N1, and H7N9 avian influenza viruses (AIVs). In antibody-modified micropore arrays, fluorescent images of micropores were observed after sandwich immunoreaction. According to their result, each fluorescent nanosphere on micropores shows single virus detection ability. When three viruses were present in the sample, these viruses can be observed simultaneously according to their fluorescence signal with a LOD of $0.02 \mathrm{pg} / \mathrm{mL}$.

\subsubsection{Colorimetric}

Colorimetric detection techniques, which offer the possibility of detecting with a naked eye, can be highly preferred because of their low-cost and rapid measurement features. Direct and sensitive detection can be performed with these systems based on the reactions or aggregation of nanoparticles [208].

Detection of influenza A H1N1 and H3N2 from cell lysate and clinical specimens taken from the throat or nose was conducted on a rapid, easy-to-use and lightweight paper-based immunochromatographic strip (ICS) [209]. A sandwich 
immunoassay was performed using AuNP/gold enhancement substrate. The paper-based POC system was offered multiplexed detection from $5 \mu \mathrm{L}$ sample with a LOD of $2.7 \times 10^{3}$ plaque-forming units (PFU) and $2.7 \times 10^{4} \mathrm{PFU}$ for $\mathrm{H} 1$ and $\mathrm{H} 3$, which are surface glycoproteins on $\mathrm{H} 1 \mathrm{~N} 1$ and $\mathrm{H} 3 \mathrm{~N} 2$, respectively. In another paper-based detection system, DNA products of viruses such as MERS-CoV were detected [210]. Color change was observed with the help of nanoparticle aggregation resulting from the complex formation of target DNA and a specific probe called pyrrolidinyl peptide nucleic acid (acpcPNA). When there was no complementary DNA in the environment, an aggregation was formed by the interaction of silver nanoparticles (AgNPs) and acpcPNA, and thereby the color turned from yellow to red. This paper-based method was provided high-sensitive, rapid, and affordable colorimetric detection even in the presence of limited resource settings. LOD of this system was found as $1.53 \mathrm{nM}$ for MERS-CoV. In another study, influenza A was detected by using a multiplex RT-LAMP with an immunochromatographic strip (ICS) containing sample field, conjugate pad, detection field, and absorbent pad (Fig. 2c) [211]. RT-LAMP products labeled with biotin were bound with AuNPs coated with streptavidin and IgG. Thereby, the gold nanoparticles were targeted to bind to the anti-IgG in the control line. Influenza A subtypes were amplified in $40 \mathrm{~min}$ and detected in $15 \mathrm{~min}$ down to 10 copies. It was also provided high accuracy of subtyping and detection from the nasal swab samples.

In a study of color-based LAMP virus detection, the nucleic acid products of the H1N1 virus were detected on a microfluidic chip controlled and monitored via a smartphone [212]. The extraction of the viral sample, cleansing, the application of the LAMP method, and the determination of the detection result were all included in the designed platform that was consisted of motors, Arduino control circuit, microfluidic chip, sensors for color and temperature monitoring, and modules for photo-interrupter and thermal control. The extraction of virus in microfluidic chip was procured via using functionalized magnetic beads. Colorimetric detection of LAMP product provided LOD of $3.2 \times 10^{-3}$ HAU for H1N1 with an assay time of $40 \mathrm{~min}$. Another colorimetric-based LAMP system was developed to detect multiple respiratory viruses in the microfluidic chip [23]. The extracted nucleic acids of H1N1, $\mathrm{H} 3 \mathrm{~N} 2, \mathrm{H} 5 \mathrm{~N} 1$, and H7N9 viruses were introduced in the microchannels and a color-based detection was provided via a real-time LAMP. It was shown that it could detect multiple respiratory viruses with a specificity of up to $100 \%$ and a sensitivity of up to $96 \%$ in clinical samples. LOD of $2-4 \mathrm{fg} /$ $\mu \mathrm{L}$ can be obtained in this chip with a sample taken from the throat.

A DNA hydrogel formation-based rolling circle amplification system called DhITACT-TRail was reported for MERSCoV detection [213]. By using a microfluidic system containing 3 different channels (sample, negative control, and positive control), it was possible to detect viral pathogens both with the naked eye and fluorescently within $2 \mathrm{~h}$ and $30 \mathrm{~min}$, respectively. With the introduction of the RNA extract into the channel, the target base pair is attached to the primary base pairs on the surface and hybridization has occurred. In order to show the repeatability feature, analyzes were made with false serum and the detection limit was found as $6 \times 10^{7}$ copies/device.

\subsubsection{Others}

Surface-enhanced Raman Scattering-based lateral flow immunoassay strip was developed for the detection of influenza A H1N1 and human adenoviruses using dual-layer Raman dye molecule conjugated $\mathrm{Fe}_{3} \mathrm{O}_{4} @ \mathrm{Ag}$ magnetic tags [214]. LOD was found for the H1N1 $50 \mathrm{PFU} / \mathrm{mL}$ and $20 \mathrm{PFU} / \mathrm{mL}$ for human adenovirus. This system is 2000 times more sensitive than the standard ICS. There are also $\mathrm{THz}$ plasmonic metasensor-based biosensors designed to detect SARSCOV-2 spike proteins in $80 \mathrm{~min}$ using toroidal resonances [215]. To increase the binding power of target biomolecules, functionalized AuNPs were added to multi-pixel metallic metasurfaces. These features allowed to reach a LOD value of about $4.2 \mathrm{fmol}$ in $15 \mu \mathrm{L}$ solution.

\subsection{Electrical detection techniques}

Electrical detection has been used for direct detection of targets by using micro and nanofabricated electrodes, field-effect transistors, and semiconductor materials [216-219]. Detection can be achieved using electrical simple instrumentation with reduced response time and signal noise, and with increased sensitivity and portability [220].

The concentration of the influenza viruses collected from patients is very low. Therefore, it is required to amplify nucleic acid samples from viruses and PCR techniques are performed as a "gold standard" method [221]. RT-PCR chip was proposed for rapid detection of influenza A virus [222]. The chip was composed of four parts, which were the realtime reaction part, denaturation part, thermal cycles part, and pressurizing part. It offered a solution to the problem of generation of air bubbles encountered in continuous-flow microfluidic PCR systems by using a pressurizing channel located before the outlet. After reaction in the RT-PCR chip, the samples collected from the outlet were analyzed with disposable electrical printed (DEP) chips and electrochemical signals were measured using square wave voltammetry (SWV). Methylene Blue (MB) was used as an electrochemical hybridization indicator for electrochemical detection by carbon printed electrodes. Decrease in the amount of free electroactive $\mathrm{MB}$ was related to increased positive samples because MB bound to DNA. Thereby, MB reduction peak currents confirmed the detection of influenza A virus. Similarly, 
cDNA of the SARS-CoV-2 virus was detected using a lowcost silicon-based integrated Point-of-Need transducer (TriSilix) [223]. They used an electrical heater, temperature sensor, and electrochemical sensor on the chip for electrochemical-based detection with MB. A handheld potentiostat was used to obtain cyclic and square wave voltammograms and the system achieved detection of $1 \mathrm{pg}$ of cDNA of SARS-CoV-2 with 40 min PCR cycling.

Influenza A virus detection system was also developed for distinguishing subtypes of the virus [221]. This system enabled amplification and detection processes with two modules. Basically, the first module (PCR module) was used to amplify nucleic acids from target strains (i.e., FluA and H1N1). Amplified target strains were then transported to the second module (sensing module). In this module, silicon nanowire (SiNW) immobilized with PNA probes for FluA or H1N1 was used for real-time electrical detection. In this system, label-free and multiplexed detection of subtypes of influenza A was achieved with the advantages of low sample consumption, high specificity, and sensitivity (20-30 fg/ $\mu \mathrm{L})$. SiNW field-effect transistor (FET)-based biosensor was developed for reusable and ultrasensitive virus detection with reversible surface functionalization strategy with a disulfide linker [224]. In the system, monoclonal antibody was used as a receptor for avian influenza virus detection with a LOD of $10^{-17} \mathrm{M}$.

Detection of DNA parts of avian influenza was achieved using a carbon nanotube (CNT)-based biosensor [225]. Two different chemiresistor-based sensors have been developed using semiconductor single-walled CNT and multi-walled CNT. CNTs immobilized with DNA probe allowed detection of the unlabeled virus sequence in less than $15 \mathrm{~min}$. LOD of 2 $\mathrm{pM}$ and $20 \mathrm{pM}$ were achieved for single-wall CNT and multiwalled CNT, respectively.

Reduced graphene oxide (rGO) transistor was used to detect gene parts of avian influenza [226]. On this device, three different immobilization techniques for DNA probes were evaluated and it was shown that the extended long capture probe immobilized by $\pi-\pi$ stacking interaction has a higher sensitivity and stability compared to short capture probe ( $\pi-\pi$ interaction) and covalent immobilization via linker. The rGO transistor provided detection down to $5 \mathrm{pM}$ with an assay time of $1 \mathrm{~h}$. In another microfluidic chip using rGO sheets, H1N1 virus particles were detected without labels and sample preparation step [220]. The rGO surface was functionalized with monoclonal antibodies specific to the H1N1 virus. The electrochemical sensor detecting changes in chronoamperometric current showed a LOD of $0.5 \mathrm{PFU}$ per milliliter. FET-based microfluidic device was also developed by coating graphene sheet with specific antibody for detection of SARS-CoV-2 spike protein (Fig. 3a) [227]. This device enabled rapid and selective detection of SARS-CoV-2 from directly nasopharyngeal swab suspended in universal transport medium with a LOD of $2.42 \times 10^{2}$ copies $/ \mathrm{mL}$.
In another study, an alternative microfluidic biosensor platform was designed and developed to detect H1N1 [228]. Label-free detection of viruses was conducted through electron interaction and provided through covalent bond between DNA aptamers and functionalized conductive polymer microelectrodes. The developed platform measured the influenza A virus (H1N1) concentration in saliva and provided fast (less than $15 \mathrm{~min}$ ), stable, sensitive, low-cost, and selective detection using impedance measurements. H1N1 virus particles were also detected using a combination of colorimetric immunoassay and electrochemical impedance spectroscopy (EIS) [229]. Filtration of the sample was achieved by using pads with large and small pores as $11 \mu \mathrm{m}$ and $0.45 \mu \mathrm{m}$, respectively, and the antigen-antibody structures were concentrated on the conjugate pad. It has been stated that a more reliable detection is provided by using the combined method. H1N1 virus was detected down to $5 \mathrm{PFU} / \mathrm{mL}$ from PBS and saliva in $6 \mathrm{~min}$ via this sensor. Multiple detection of respiratory viruses (H1N1, H5N1, and H7N9) was also performed on an immunosensor [230]. The immunosensor chip enabling simultaneous and quantitative detection was constructed with the $\mathrm{ZnO}$ nanorods (NRs). Captured antibodies of three viruses were immobilized on $\mathrm{ZnO}$ NRs and sandwich ELISA procedure was conducted with a detection antibody labeled with HRP. Oxidation current resulting from the reaction of HRP and 3,3',5,5'-tetramethylbenzidine (TMB) was used to detect influenza viruses down to $1 \mathrm{pg} / \mathrm{mL}$ (Fig. 3b) [230].

Detection of influenza A H9N2 was conducted with iron magnetic nanoparticles (MNPs) and AuNPs used for isolation and detection, respectively [231]. Antibody-conjugated MNPs formed a sandwich-like complex with Fetuin-AuNPs in the presence of target influenza virus. The virus detection was carried out based on gold catalysis and provided the rapid detection of H9N2 at a titer less than 16 HAU. An ultrasensitive device (eCovSens) using a screen-printed carbon electrode (SPCE) was developed for the detection of SARS$\mathrm{CoV}-2$ virus and compared with commercial potentiostat using fluorine-doped tin oxide (FTO) electrode, which was conducted by immobilization of AuNPs used for both immobilization of monoclonal antibody of SARS-CoV-2 and amplification of electrochemical signals [232]. This device offered a very rapid analysis down to $10-30 \mathrm{~s}$ using $20 \mu \mathrm{L}$ sample volume of saliva with a LOD of $90 \mathrm{fM}$. Moreover, LOD is reduced to $10 \mathrm{fM}$ in standard buffer. Even though the detection limits of the two systems were similar to commercial potentiostat, the developed device had advantages such as being portable and cost-effective. A microfluidic chip was also developed for influenza virus or influenza hemagglutinin detection [233]. Working method of the chip was based on two main steps that are isolation by paramagnetic beads and detection of the target electrochemically. Streptavidin-biotin affinity was utilized for isolated hemagglutinin on paramagnetic beads was labeled with cadmium 
(a)

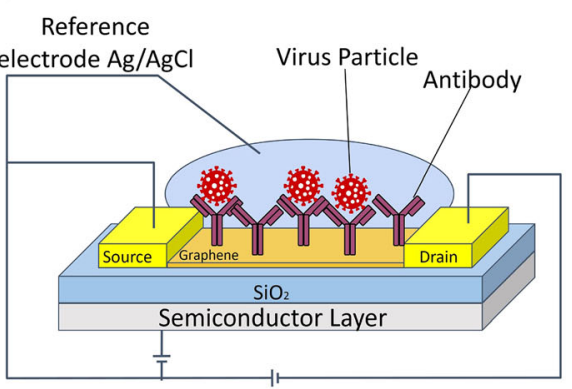

(b)

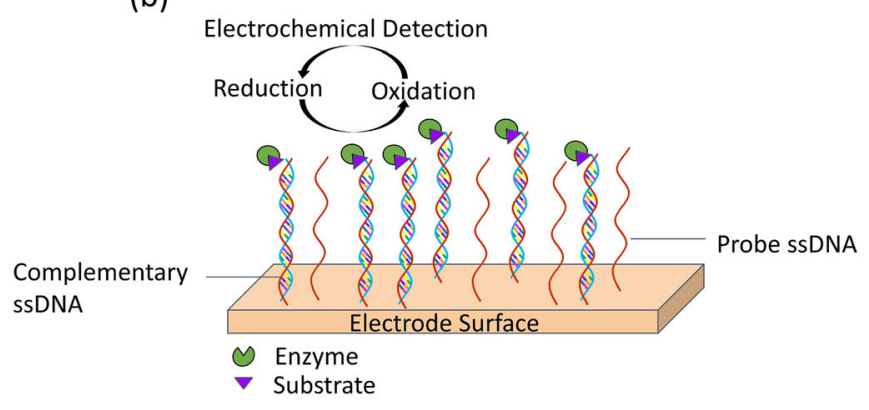

Fig. 3 Illustrations of electrical-based methods for the detection of respiratory viruses or their products. a FET-based biosensor, $\mathbf{b}$ Electrochemical biosensors to detect DNA fragments

sulfide (CdS) QDs and it was detected by voltammetry measuring changes in cadmium signals.

\subsection{Other detection techniques}

Influenza A virus was detected via the novel surface acoustic wave (SAW) sensor capturing H1N1 viral antigen from liquid [234]. The SAW sensor surface was functionalized to immobilize HA antibodies for influenza A. The system includes a syringe pump system to control fluidic flow, microwave probes, and electrodes. The SAW sensor allowed sensitive detection down to $1 \mathrm{ng} / \mathrm{mL}$ antigen on the functionalized SAW surface using Love wave. Offering reliable detection, this approach could offer a fast and sensitive virus detection platform as a clinical diagnostic compared to commercial kits with low specificity.

Quartz-crystal microbalance (QCM)-based detection was achieved for the influenza virus RNA detection [235]. Target genome in the microfluidic channel was captured by PNA immobilized on QCM electrode. Gold colloid was used to increase virus RNA weight to increase sensitivity, and LOD was found as $10^{6} \mathrm{PFU} / \mathrm{mL}$ for this mass-based detection.

\section{Commercially available microfluidic solutions}

Cepheid Xpert® Xpress (USA) is an automated molecular device for testing SARS-CoV-2, flu A, flu B, and RSV [236]. This device includes sample preparation, nucleic acid amplification, and detection in one. It has a simple design to use without professionals and gives positive results around $30 \mathrm{~min}$ and it has acquired Emergency Use Authorizations (EUA) from FDA. Roche cobas ${ }^{\circledR}$ (USA) is a real-time RTPCR test designed for the qualitative detection of nucleic acids from SARS-CoV-2 [236]. The Roche platform is a batchbased platform that can perform multiple tests and contains 90 samples/runs every $90 \mathrm{~min}$. Cobas ${ }^{\circledR}$ has been authorized by FDA under an EUA. Isothermal Microfluidic Chip Analyzer RTisochip ${ }^{\mathrm{TM}}(\mathrm{CHN})$ is developed for independent analysis of nucleic acid with high throughput, flexibility, high capacity, high accuracy, low cross-contamination, high efficiency, and multi-sample analysis [237]. It was developed by CapitalBio Technology Corporation and certificated by CE. This kit can detect SARS-CoV-2 and 5 other types of respiratory viruses. BioFire ${ }^{\mathrm{TM}}$ Filmarray ${ }^{\circledR}$ (USA) system is a microfluidic-based detection system that enables extraction, purification, and PCR amplification of nucleic acid in a single chip [22]. This device gives 19 viral and 4 bacterial target detection results around $1 \mathrm{~h}$ and it is so easy to use without pipetting or measuring the sample [238]. It was certificated by FDA, CE-IVD, and TGA and is currently used for fighting SARS-CoV-2. be.well ${ }^{\mathrm{TM}}$ by Alveo Technologies (USA) provides a rapid and easy-to-use detection platform to detect flu $\mathrm{A} / \mathrm{B}$, SARS-CoV-2, and RSV and to manage these viral diseases via be.well ${ }^{\mathrm{TM}}$ cloud-based applications. This platform is integrated with a smartphone and can provide a result within $30 \mathrm{~min}$. The platform includes a microfluidic channel that can amplify nucleic acids in real-time [239]. Veredus Laboratories (SG) developed VereFlu Chip which is a nucleic acid-based test used for the qualitative detection, differentiation, and identification of influenza A (H1, H3, H5, H7, H9), influenza B viruses, and 2009 pandemic H1N1 in a single test [240]. Also, VereCoVTM Detection Kit was developed and used for the qualitative detection of the nucleic acid of MERS-CoV, SARS-CoV-1, and SARS-CoV-2 by integrating PCR and microarray. This detection kit can detect and differentiate 3 coronaviruses types in a single test for about $2 \mathrm{~h}$ [241]. Alere BinaxNOW® Influenza A \& B Card developed by Abbott Company (USA) is an immunochromatographic assay for the rapid detection of influenza A and B [242]. It enables simultaneous, qualitative detection for two types of influenza viruses in just $15 \mathrm{~min}$ by using samples from nasal/ nasopharyngeal swab and nasal wash/aspirate. Current technology developed by Abbott Company for detection of influenza A and B is the ID NOWTM which is an isothermal nucleic acid amplification-based POC device [243]. It gives a negative result within $13 \mathrm{~min}$ and a positive result within $5 \mathrm{~min}$ from swab samples. The company has also developed ID NOW $^{\text {TM }}$ RSV and ID NOW ${ }^{\text {TM }}$ COVID-19 devices for nucleic 
acid detection of RSV and SARS-CoV-2, respectively [244, 245]. Quidel Corp. developed QuickVue ${ }^{\circledR}$ (USA) test which is a rapid lateral flow immunoassay, and it can detect influen$\mathrm{za}$, adenovirus, bordetella, SARS-CoV-2, RSV, and some other respiratory viruses [246-248]. The QuickVue ${ }^{\circledR}$ influenza test kit gives results in $10 \mathrm{~min}$ [249], and it takes $15 \mathrm{~min}$ in the RSV test [250]. The kit has relatively low sensitivity compared to its high specificity [247, 251]. Also, the results of the statistical measures of the performance change by specimen collection method and age group [249, 251]. Besides these, there are so many different tests and devices for the detection of SARS-CoV-2 and the other respiratory viruses [252].

\section{Challenges of virus detection}

Key point of the successful microfluidic chips and sensors design is related with the main eight performance factors which are stability, sensitivity, selectivity, detection range, response time, repeatability, LOD, and lifetime [253, 254]. Low detection limit is required to detect infection in early stages for rapid and effective treatment. Multiple detection systems are important for specific, sensitive, and accurate diagnosis of the target virus or its subtypes [22]. Also, more than one virus infection at the same time can be seen in some cases. In this point, multiple detection is more advantageous to understand severity of the illnesses in people with different viral loading and compare the impact of the viruses in mixed infection [255]. Hence, selectivity is a crucial parameter in these systems. Microfluidic platforms should also offer portable, low-cost, easy-to-use, and fast detection schemes for rapid and point-of-care assessment of respiratory viruses. Storage conditions and operational procedures of these platforms need to be easy-to-handle for increasing access to rapid diagnosis even in rural areas. In microfluidic devices, environment and external influences have an effect on detection of virus components or virus itself. Temperature has a primary effect on many microfluidic devices. It severely affects detection methods using PCR and LAMP [222]. Temperature should be controlled for sensitive and efficient detection. Heating is also a factor that must be controlled in designed devices, as it affects the electrochemical interaction, optical signals, microwaves, and the speed of molecular reactions in the sample [256]. Mechanical effects are also factors affecting the detection in microfluidic devices. Pressure [257], fluid dynamics [258], mixing effect [259], etc. may change the efficiency of the detection. External electric [260] and magnetic [204] fields can also affect the measurement techniques and detection efficiency of microfluidic devices using magnetic, electronic, and electrochemical techniques. Therefore, microfluidics devices should be tested for external effects also so that precautions could be taken to eliminate these adverse effects on the detection performance.

There are different protocols and methods that should be used to keep the signal levels at the highest level in the determination of respiratory tract viruses. The most important steps are specimen collection, extraction, amplification, and measuring signal levels for sensitive detection [11]. Although labeled detection methods offer sensitive direct detection, labeling process increases assay time and cost [261].

The process of collecting samples/specimens from different locations of the body of respiratory viruses from human varies from virus to virus [34, 262]. Respiratory virus samples can be collected from feces, serum, sputum, bronchial lavage, nasal swab, nasal brush, nasal wash, blood, tear, oropharyngeal swab, pharyngeal swab, nasopharyngeal wash, nasopharyngeal aspirate, conjunctival swab, lung biopsy, etc. [263-268]. However, collection, transport, and storage conditions of the specimen could affect detection sensitivity [264]. Sample preparation, collection, transport, and detection can be performed on a chip level using microfluidic technology [4, 269].

Samples taken for the nucleic acid-based detection of respiratory tract viruses are subjected to an extraction process so that unwanted substances are removed, and the unity of viral nucleic acids is preserved. Nowadays, different methods are used for the extraction of nucleic acids from different sources [270]. These methods include phenol-chloroform extraction, solid-phase extraction methods, the bead-based system providing extraction with magnetic control, and the filtration method provided with a filter paper. The phenol-chloroform extraction method, which can damage nucleic acids and create harmful waste after extraction, is low-cost but requires experienced technicians [271, 272]. The solid-phase extraction method, based on column and membrane, is a rapid and simpler method, but requires multiple centrifugations and laboratory devices for extraction steps [11, 273, 274]. In the magnetic bead-based extraction method, which is based on the use of functionalized magnetic beads, nucleic acids bind magnetic beads and allows isolation of nucleic acids [270, 275]. This method can require multiple washing processes $[11,276]$. It can be also conducted in microfluidic platforms using functionalized magnetic beads [277]. In extraction by filtration method, commercially available paper and membrane structures allow isolation of nucleic acids [278, 279]. This method, which is quite affordable and simple, is also suitable for use in microfluidic platforms.

Nucleic acid amplification methods for the virus detection have many advantages over serological tests. Nucleic acid amplification offers sensitive detection because produced antibodies are not able to be detected at the early phase of the virus [11]. PCR, LAMP, recombinase polymerase amplification (RPA), helicase-dependent amplification (HDA), exponential amplification reaction (EXPAR), nucleic acid sequence-based amplification (NASBA), transcription- 
mediated amplification (TMA), and ligase chain reaction (LCR) are the types of amplification methods [280-282]. PCR is performed with a number of temperature cycles including denaturation, annealing, and extension by the help of DNA polymerase [269]. LAMP is performed at fixed temperature $\left(65^{\circ} \mathrm{C}\right) ; 10^{9}$ amplicon production is achieved in less than $1 \mathrm{~h}$. LAMP can be easily integrated to microfluidic systems and the detection of amplified products can be conducted even with naked eye inspection $[269,283]$. Due to low isothermal incubation temperature, sensitivity, and high tolerance to impurities in sample, RPA has significant utilization in microfluidics [284]. HDA uses ds-DNA unwinding activity of helicase to separate strand and produced amplicons by strand displacing DNA polymerase [285]. HDA is also one of the mostly used amplification techniques in microfluidics due to its simplicity and sensitivity [269]. TMA and NASBA amplify RNA using RNase and RNA polymerase activity. RNase digests the RNA and RNA polymerase produces copies. NASBA is performed isothermally thus, does not require a thermocycler. In LCR, ds-DNA is denatured, and primers anneal to each strand, then ligation occurs by DNA ligase [286]. For nucleic acid amplifications, microfluidic platforms offer many advantages, such as simple heat transfers due to their small size, rapid detection, portability, high specificity, and automation [287, 288].

Immobilization of capturing agents is also the key point for the desired detection [289]. The capturing agents can be grafted on surfaces using physical adsorption, covalent attachment, bioaffinity immobilization, streptavidin-biotin immobilization, etc. depending on the chip surface and properties of capturing agents [290-292]. Silicon is mostly used material for the integrated circuit devices and microelectromechanical systems. However, opaqueness of silicon can limit the optical imaging and requirement of cleanroom environment can increase the cost of fabrication [293]. Glass substrates are wellsuited generally for optical-based detection methods but it has some disadvantages such as brittle and not easily processed [294]. PDMS is one of the most favored materials due to its low-cost, flexible, and transparent structure [295]. PDMS can be easily fabricated using a soft lithography technique where microfabricated or even 3D printed molds can be used [20]. The limited resistance to organic solvents and challenges of hydrophobic structure of PDMS limits its utilization [294]. Moreover, hybrid fabrication technique utilizing bonding of 3D printed structures with surface functionalizes surfaces enhances the usability of 3D printed technology in microfluidicbased sensing methods [20]. For direct detection of intact target viruses or virus residues, antibody, aptamer, DNA probe, and PNA probe are utilized in microfluidic devices as capturing agents of targets [294, 296-298]. Recently, aptamers are used instead of antibodies due to their less sensitivity to environmental factors [292].

\section{Summary and Outlook}

During viral infection, expression of IgM antibodies takes place after 3-7 days of infection, and IgG antibodies can be detectable after 8 days which is the main challenge for the viral detection [299]. The most disadvantage of $\mathrm{IgG} / \mathrm{IgM}$ detection is that produced antibodies can react with crossreactive antibodies that cause false positives of patients without SARS-CoV-2 [299]. According to WHO recommendation, serological testing should be used to understand if someone has ever been infected and assessment of immunity, not for clinical diagnostics [300]. On the other hand, even if the immune system is not yet activated, viruses and their contents can be detected directly for early diagnosis. Thus, direct detection methods are more efficient for the precise virus detection.

Saliva, swab samples, nasal fluid, and blood are analyzed for the direct detection of respiratory viruses by various detection methods. Conventional methods for the detection of viruses such as PCR and ELISA have some disadvantages such as the requirement for trained personnel as well as costly and complex equipment. Microfluidic technologies offer accurate and specific methods for direct detection of respiratory tract viruses. Direct detection techniques play an important role for the diagnosis of respiratory diseases with high specificity and sensitivity. Microfluidic systems enable to reduce sample consumption, assay time, and cost of tests without compromising form assay sensitivity. Hence, microfluidic-based detection technologies are beneficial in pandemic and epidemic situations by providing rapid, portable, and accurate detection of viruses.

The use of microfluidic technologies provides many advantages as compared with conventional methods. Since microfluidic devices are time- and cost-effective devices, preference of these devices is increased over time. Also, detection efficiencies increase through miniaturization and the use of small volumes [301, 302]. Microfluidic systems for detection of respiratory virus detection are summarized in Table 1. Each detection method has different advantages. For instance, absorbance-based detection can reach low LOD. Fluorescentbased detection focuses on the direct detection of virus particles by reducing analysis time. Although colorimetric-based methods have a longer analysis time compared to other optical methods, they allow naked-eye detection. Many methods have been applied in electrical detection and their general features are short analysis time with a low LOD. Thus, different detection methods can be preferred when considering extraction, target analyte, LOD, and analysis time. Since electrical detection can provide portable and label-free detection, this detection strategy can be a good candidate for rapid virus detection onsite. Since amplification and labeling strategies can increase assay time and cost, new nanomaterials, or nanostructures 
Table 1 Summary of microfluidic systems used for detection of respiratory virus detection

\begin{tabular}{|c|c|c|c|c|c|c|}
\hline Reference & $\begin{array}{l}\text { Detection } \\
\text { method }\end{array}$ & Extraction & Virus & Target analyte & LOD & $\begin{array}{l}\text { Assay } \\
\text { time }\end{array}$ \\
\hline 188 & Absorbance & - & SARS-CoV-2 & N-protein & $10^{-18} \mathrm{M}$ & $15 \min$ \\
\hline 187 & Absorbance & - & SARS-CoV-2 & Surface proteins & 100 units $/ \mathrm{mL}$ & $\sim 1 \mathrm{~h}$ \\
\hline 189 & Absorbance & - & H1N1 & Virus particle & $2.9 \times 10^{3} \mathrm{PFU} / \mathrm{mL}$ & $1 \mathrm{~h}$ \\
\hline 201 & LSPR & - & SARS-CoV-2 & $\begin{array}{l}\text { AuNIs with } \\
\text { complementary DNA } \\
\text { receptors }\end{array}$ & $0.22 \mathrm{pM}$ & $800 \mathrm{~s}$ \\
\hline 74 & SPR & $\begin{array}{l}\text { Nucleic acid } \\
\text { extraction } \\
\text { kit }\end{array}$ & $\begin{array}{l}\text { Influ A, Influ B, PIV 1, PIV 2, } \\
\text { PIV 3, RSV, SARS, ADV, } \\
\text { H1N1 }\end{array}$ & Oligonucleotides & $\begin{array}{l}5 \mathrm{nM} \text { for Influ A, } \\
1 \mathrm{nM} \text { for Influ B, } \\
1 \mathrm{nM} \text { for PIV } 1, \\
2.5 \mathrm{nM} \text { for PIV } 2,3.5 \mathrm{nM} \text { for } \\
\text { PIV 3, } 3 \mathrm{nM} \text { for RSV, } \\
0.5 \mathrm{nM} \text { for ADV, } 2 \mathrm{nM} \text { for } \\
\text { SARA, } \\
3 \mathrm{nM} \text { for H1N1 }\end{array}$ & $\sim 30 \mathrm{~min}$ \\
\hline 202 & SPR & - & H1N1 & Nucleoprotein & $\mathrm{NR}$ & NR \\
\hline 203 & Fluorescent & On-chip & SARS-CoV-2 & Nucleic acid & 10 copies $/ \mu \mathrm{L}$ & $30 \mathrm{~min}$ \\
\hline 204 & Fluorescent & - & $\mathrm{H} 1 \mathrm{~N} 1, \mathrm{H} 3 \mathrm{~N} 2$ and $\mathrm{H} 9 \mathrm{~N} 2$ & cDNA & $\begin{array}{l}0.21 \mathrm{nM} \text { for } \mathrm{H} 1 \mathrm{~N} 1,0.16 \mathrm{nM} \\
\text { for } \mathrm{H} 3 \mathrm{~N} 2,0.12 \mathrm{nM} \text { for } \\
\mathrm{H} 9 \mathrm{~N} 2\end{array}$ & $80 \mathrm{~min}$ \\
\hline 205 & Fluorescent & Yes & H1N1, H3N2 and Influenza B & Virus particle & $3.2 \mathrm{HAU}$ & $20 \mathrm{~min}$ \\
\hline 206 & Fluorescent & - & $\mathrm{H} 1 \mathrm{~N} 1, \mathrm{H} 3 \mathrm{~N} 2$ & Virus particle & $5 \times 10^{-4} \mathrm{HAU}$ & $15 \mathrm{~min}$ \\
\hline 207 & Fluorescent & - & H9N2, H1N1, H7N9 & Virus particle & $0.02 \mathrm{pg} / \mathrm{mL}$ & NR \\
\hline 209 & Colorimetric & - & $\mathrm{H} 1 \mathrm{~N} 1$ and $\mathrm{H} 3 \mathrm{~N} 2$ & $\begin{array}{l}\text { Proteins inside and } \\
\text { outside of the } \\
\text { influenza virus }\end{array}$ & $\begin{array}{l}2.7 \times 10^{3} \mathrm{PFU} / \text { assay for } \mathrm{H} 1 \\
\text { and } 2.7 \times 10^{4} \mathrm{PFU} / \text { assay for } \\
\mathrm{H} 3\end{array}$ & $1 \mathrm{~h}$ \\
\hline 210 & Colorimetric & $\begin{array}{l}\text { Experimental } \\
\text { approach }\end{array}$ & MERS-CoV & DNA parts & $1.53 \mathrm{nM}$ & NR \\
\hline 211 & Colorimetric & $\begin{array}{l}\text { Nucleic acid } \\
\text { extraction } \\
\text { kit }\end{array}$ & $\mathrm{H} 1 \mathrm{~N} 1, \mathrm{H} 3 \mathrm{~N} 2$, and $\mathrm{H} 5 \mathrm{~N} 1$ & RT-LAMP products & 10 copies of viral RNA & $55 \mathrm{~min}$ \\
\hline 212 & Colorimetric & $\begin{array}{l}\text { Bead-based } \\
\text { extraction }\end{array}$ & $\mathrm{H} 1 \mathrm{~N} 1$ & RNA or DNA & $3.2 \times 10^{-3} \mathrm{HAU} /$ reaction & $40 \mathrm{~min}$ \\
\hline 23 & Colorimetric & $\begin{array}{l}\text { Bead-based } \\
\text { extraction }\end{array}$ & H1N1, H3N2, H5N1, and H7N9 & Nucleic acids & $2-4 \mathrm{fg} / \mu \mathrm{L}$ & $30 \mathrm{~min}$ \\
\hline 213 & Colorimetric & & MERS-CoV & RNA & $6 \times 10^{7}$ copies $/$ device & $2 \mathrm{~h}$ \\
\hline 214 & $\begin{array}{l}\text { Surface } \\
\quad \text { enhanced } \\
\text { raman } \\
\text { scattering }\end{array}$ & - & H1N1 and human adenovirus & Virus particle & $\begin{array}{l}50 \mathrm{PFU} / \mathrm{mL} \text { for } \mathrm{H} 1 \mathrm{~N} 1 \text { and } 20 \\
\mathrm{PFU} / \mathrm{mL} \text { for human adeno- } \\
\text { virus }\end{array}$ & NR \\
\hline 215 & Plasmonic & - & SARS-CoV-2 & Spike protein & $\sim 0.28 \mathrm{nM}$ & $\sim 80 \mathrm{~min}$ \\
\hline 222 & Electrical & $\begin{array}{l}\text { Nucleic acid } \\
\text { extraction } \\
\text { kit }\end{array}$ & Influenza A & PCR amplicon & $5.36 \times 10^{3}$ copies $/ \mu \mathrm{L}$ & $\sim 15 \mathrm{~min}$ \\
\hline 223 & Electrical & $\begin{array}{l}\text { DNA } \\
\text { extraction } \\
\text { kit }\end{array}$ & SARS-CoV-2 & cDNA & $1 \mathrm{pg}$ & $\sim 40 \mathrm{~min}$ \\
\hline 221 & Electrical & $\begin{array}{l}\text { Gel extraction } \\
\text { kit }\end{array}$ & H1N1 and H3N2 & DNA & $20-30 \mathrm{fg} / \mu \mathrm{L}$ & NR \\
\hline 224 & Electrical & - & $\mathrm{H} 5 \mathrm{~N} 2$ & Virus particle & $10-17 \mathrm{M}$ & NR \\
\hline 225 & Electrical & Yes & $\mathrm{H} 5 \mathrm{~N} 1$ & DNA parts & $2 \mathrm{pM}$ & $15 \mathrm{~min}$ \\
\hline 226 & Electrical & - & $\mathrm{H} 5 \mathrm{~N} 1$ & DNA parts & $5 \mathrm{pM}$ & $1 \mathrm{~h}$ \\
\hline 220 & Electrical & - & H1N1 & Virus particle & $0.5 \mathrm{PFU} / \mathrm{mL}$ & NR \\
\hline 227 & Electrical & - & SARS-CoV-2 & Spike protein & $2.42 \times 10^{2}$ copies $/ \mathrm{mL}$ & $>1 \min$ \\
\hline 229 & Electrical & - & H1N1 & Virus particle & $5 \mathrm{PFU} / \mathrm{mL}$ & $6 \mathrm{~min}$ \\
\hline 230 & Electrical & - & $\mathrm{H} 1 \mathrm{~N} 1, \mathrm{H} 5 \mathrm{~N} 1$ and H7N9 & Virus particle & $1 \mathrm{pg} / \mathrm{mL}$ of each virus & NR \\
\hline 231 & Electrical & - & $\mathrm{H} 9 \mathrm{~N} 2$ & Virus particle & $16 \mathrm{HAU}$ & $160 \mathrm{~s}$ \\
\hline
\end{tabular}


Table 1 (continued)

\begin{tabular}{|c|c|c|c|c|c|c|}
\hline Reference & $\begin{array}{l}\text { Detection } \\
\text { method }\end{array}$ & Extraction & Virus & Target analyte & LOD & $\begin{array}{l}\text { Assay } \\
\text { time }\end{array}$ \\
\hline 232 & Electrical & - & SARS-CoV-2 & Spike protein & $\begin{array}{l}90 \mathrm{fM} \text { in spiked saliva sample, } \\
10 \mathrm{fM} \text { in standard buffer }\end{array}$ & $10-30 \mathrm{~s}$ \\
\hline 233 & Electrical & - & $\mathrm{H} 5 \mathrm{~N} 1$ & $\begin{array}{l}\text { Surface antigen } \\
\text { (hemagglutinin) }\end{array}$ & - & $45 \mathrm{~min}$ \\
\hline 234 & Acoustic & - & H1N1 & HA antigen & $1 \mathrm{ng} / \mathrm{mL}$ & NR \\
\hline 235 & Mass & - & Influenza & RNA & $10^{6} \mathrm{PFU} / \mathrm{mL}$ & NR \\
\hline
\end{tabular}

$N R$ not reported

could be utilize as sensor elements to enhance sensitivity of electrical detection methods further.

All specified commercial diagnostic kits and medical devices must obtain conformity certificates from the approving authorities (FDA, NMPA, etc.). Microfluidic diagnostic devices can be commercialized in accordance with specified quality parameters and performance criteria determined by these approving institutions. For this reason, the features that distinguish commercial products from each other are generally the diagnostic method, speed of diagnosis, LOD, diagnostic capacity, etc. When we look at commercial products in the detection of respiratory tract viruses, it is shown that products where all assay stages such as sample preparation, extraction, and amplification are performed on chip are more efficient. Moreover, it is of great importance that commercial devices can make rapid and also multiplex detections.

Microfluidic technologies can offer accurate and sensitive detection of respiratory tract viruses. Direct detection techniques enhance the specificity and sensitivity of virus detection. This review focused on the direct detection technologies developed in microfluidic systems for the detection of respiratory. These techniques could reduce sample volume, assay time, and test cost and they could also provide portable, rapid, and sensitive detection of respiratory viruses that could be used for controlling outbreaks with rapid assessment of viruses.

Acknowledgements This study is funded by the Scientific and Technological Research Council of Turkey (217S518) to H.C.T.; Qatar National Research Fund (QNRF), National Priority Research Program (NPRP 10-0123-170222) to H.C.Y.; and QNRF Rapid Response Call (RRC) Award to H.C.Y. and M.K.A.A. (RRC-2-076). Financial support from the Scientific and Technological Research Council of Turkey, 2211A BIDEB doctoral scholarship (E.A.T. and O.S.) and the Council of Higher Education for 100/2000 doctoral scholarship (B.K., E.A.T., M.K., and O.S.) are gratefully acknowledged.

\section{Declarations}

Conflict of interest The authors declare no competing interests.
Open Access This article is licensed under a Creative Commons Attribution 4.0 International License, which permits use, sharing, adaptation, distribution and reproduction in any medium or format, as long as you give appropriate credit to the original author(s) and the source, provide a link to the Creative Commons licence, and indicate if changes were made. The images or other third party material in this article are included in the article's Creative Commons licence, unless indicated otherwise in a credit line to the material. If material is not included in the article's Creative Commons licence and your intended use is not permitted by statutory regulation or exceeds the permitted use, you will need to obtain permission directly from the copyright holder. To view a copy of this licence, visit http://creativecommons.org/licenses/by/4.0/.

\section{References}

1. Pattemore, P. K. \& Jennings, L. C. Epidemiology of respiratory infections. in Pediatric Respiratory Medicine 435-452 (Elsevier, 2008). https://doi.org/10.1016/B978-032304048-8.50035-9.

2. D. Zhang et al., Epidemiology characteristics of respiratory viruses found in children and adults with respiratory tract infections in southern China. Int. J. Infect. Dis. 25, 159-164 (2014)

3. C. Troeger et al., Estimates of the global, regional, and national morbidity, mortality, and aetiologies of lower respiratory infections in 195 countries, 1990-2016: a systematic analysis for the Global Burden of Disease Study 2016. Lancet Infect. Dis. 18, 1191-1210 (2018)

4. A. Basiri et al., Microfluidic devices for detection of RNA viruses. Rev. Med. Virol. (2020). https://doi.org/10.1002/rmv.2154

5. World Health Organization. WHO coronavirus disease (COVID19) dashboard. (2020).

6. World Health Organization. Q\&A: How is COVID-19 transmitted? https://www.who.int/emergencies/diseases/novel-coronavirus-2019/advice-for-public/myth-busters (2020).

7. CDC. Symptoms of coronavirus. https://www.cdc.gov/coronavirus/2019-ncov/downloads/COVID19-symptoms.pdf (2020).

8. V. Yamamoto et al., COVID-19: Review of a 21st century pandemic from etiology to neuro-psychiatric implications. J. Alzheimers Dis. 77, 459-504 (2020)

9. CDC. Long-term effects of COVID-19. https:// www.mayoclinic.org/diseases-conditions/coronavirus/in-depth/ coronavirus-long-term-effects/art-20490351 (2020).

10. M.A. Ellul et al., Neurological associations of COVID-19. Lancet Neurol (2020). https://doi.org/10.1016/S1474-4422(20)30221-0

11. Z. Qin, R. Peng, I.K. Baravik, X. Liu, Fighting COVID-19: integrated micro- and nanosystems for viral infection diagnostics. Matter 3, 628-651 (2020) 
12. Y. Li et al., Microfluidics-based systems in diagnosis of Alzheimer's disease and biomimetic modeling. Micromachines 11, $787(2020)$

13. L.Y. Yeo, H.-C. Chang, P.P.Y. Chan, J.R. Friend, Microfluidic devices for bioapplications. Small 7, 12-48 (2011)

14. M.L. Kovarik et al., Micro total analysis systems: fundamental advances and applications in the laboratory, clinic, and field. Anal. Chem. 85, 451-472 (2013)

15. B. Nasseri et al., Point-of-care microfluidic devices for pathogen detection. Biosens. Bioelectron. 117, 112-128 (2018)

16. M.A. Mujawar et al., Nano-enabled biosensing systems for intelligent healthcare: towards COVID-19 management. Mater. Today Chem. 17, 100306 (2020)

17. A. Kaushik, Manipulative magnetic nanomedicine: the future of COVID-19 pandemic/endemic therapy. Expert Opin. Drug Deliv., 1-4 (2020). https://doi.org/10.1080/17425247.2021.1860938

18. L. Dai et al., Microfluidics-based microwave sensor. Sensors Actuators A Phys. 309, 111910 (2020)

19. S. Halldorsson, E. Lucumi, R. Gómez-Sjöberg, R.M.T. Fleming, Advantages and challenges of microfluidic cell culture in polydimethylsiloxane devices. Biosens. Bioelectron. 63, 218-231 (2015)

20. S. Kecili, H.C. Tekin, Adhesive bonding strategies to fabricate high-strength and transparent 3D printed microfluidic device. Biomicrofluidics 14, 024113 (2020)

21. C. Simpson, S.S. Lee, C.-S. Lee, Y. Yamauchi, Microfluidics: an untapped resource in viral diagnostics and viral cell biology. Curr. Clin. Microbiol. Rep. 5, 245-251 (2018)

22. J. Zhuang, J. Yin, S. Lv, B. Wang, Y. Mu, Advanced "lab-on-achip" to detect viruses - current challenges and future perspectives. Biosens. Bioelectron. 163, 112291 (2020)

23. R. Wang et al., Rapid detection of multiple respiratory viruses based on microfluidic isothermal amplification and a real-time colorimetric method. Lab Chip 18, 3507-3515 (2018)

24. P. Paliwal et al., Grand challenges in bio-nanotechnology to manage the COVID-19 pandemic. Front. Nanotechnol. (2020). https:// doi.org/10.3389/fnano.2020.571284

25. WHO report on global surveillance of epidemic-prone infectious diseases - influenza. (2020).

26. S. Ghebrehewet, P. Macpherson, A. Ho, Influenza. BMJ (Online) 355 (2016)

27. D. Dharmapalan, Influenza. Indian J. Pediatr. 87, 828-832 (2020)

28. J.K. Taubenberger, D.M. Morens, The pathology of influenza virus infections. Annu. Rev. Pathol.: Mechanisms of Disease 3, 499-522 (2008)

29. WHO | WHO report on global surveillance of epidemic-prone infectious diseases. WHO (2015).

30. D. Flecknoe, B. Charles Wakefield, A. Simmons, Plagues \& wars: the 'Spanish Flu' pandemic as a lesson from history. Med Confl Surviv 34, 61-68 (2018)

31. J.R. Kerr, Swine influenza. J. Clin. Pathol. 62, 577-578 (2009)

32. Ribeiro, B. V., Cordeiro, T. A. R., Oliveira e Freitas, G. R., Ferreira, L. F. \& Franco, D. L. Biosensors for the detection of respiratory viruses: a review. Talanta Open 2, 100007 (2020).

33. A.M. Binder et al., Human adenovirus surveillance-United States, 2003-2016. MMWR Morb. Mortal. Wkly Rep. 66(1039) (2017)

34. Lynch, J. P., Fishbein, M. \& Echavarria, M. Adenovirus. in Seminars in respiratory and critical care medicine vol. 32 494 511 (@Thieme Medical Publishers, 2011).

35. J. Bautista-Gogel et al., Outbreak of respiratory illness associated with human adenovirus type 7 among persons attending Officer Candidates School, Quantico, Virginia, 2017. J. Infect. Dis. 221, 697-700 (2020)
36. H.M. Biggs et al., Adenovirus-associated influenza-like illness among college students, Pennsylvania, USA. Emerg. Infect. Dis. 24, 2117 (2018)

37. G.C. Gray et al., Adult adenovirus infections: loss of orphaned vaccines precipitates military respiratory disease epidemics. Clin. Infect. Dis. 31, 663-670 (2000)

38. A.E. Rogers et al., Outbreak of acute respiratory illness associated with adenovirus type 4 at the US Naval Academy, 2016. MSMR 26, 21-27 (2019)

39. B.L. Gurda et al., Human bocavirus capsid structure: insights into the structural repertoire of the Parvoviridae. J. Virol. 84, 5880 $5889(2010)$

40. M. Guido et al., Human bocavirus: current knowledge and future challenges. World J. Gastroenterol. (2016). https://doi.org/10. 3748/wjg.v22.i39.8684

41. T. Allander, Human bocavirus. J. Clin. Virol. (2008). https://doi. org/10.1016/j.jcv.2007.10.026

42. J. Longtin et al., Human bocavirus infections in hospitalized children and adults. Emerg. Infect. Dis. 14, 217-221 (2008)

43. S. Biacchesi et al., Genetic diversity between human metapneumovirus subgroups. Virology 315, 1-9 (2003)

44. G. Boivin et al., Virological features and clinical manifestations associated with human metapneumovirus: a new paramyxovirus responsible for acute respiratory-tract infections in all age groups. J. Infect. Dis. 186, 1330-1334 (2002)

45. B.G. van den Hoogen et al., A newly discovered human pneumovirus isolated from young children with respiratory tract disease. Nat. Med. 7, 719-724 (2001)

46. B.G. van den Hoogen, T.M. Bestebroer, A.D.M.E. Osterhaus, R.A.M. Fouchier, Analysis of the genomic sequence of a human metapneumovirus. Virology 295, 119-132 (2002)

47. J. Pan et al., Structure of the human metapneumovirus polymerase phosphoprotein complex. Nature 577, 275-279 (2020)

48. M. MacPhail et al., Identification of small-animal and primate models for evaluation of vaccine candidates for human metapneumovirus (hMPV) and implications for hMPV vaccine design. J. Gen. Virol. 85, 1655-1663 (2004)

49. N. Shafagati, J. Williams, Human metapneumovirus - what we know now. F1000Research 7, 135 (2018)

50. I. Takayama et al., Clinical evaluation of fully automated molecular diagnostic system "Simprova" for influenza virus, respiratory syncytial virus, and human metapneumovirus. Sci. Rep. 10, 13496 (2020)

51. B.G. van den Hoogen et al., Prevalence and clinical symptoms of human metapneumovirus infection in hospitalized patients. J. Infect. Dis. 188, 1571-1577 (2003)

52. S.E. Jacobs, D.M. Lamson, St. George, K. \& Walsh, T. J. Human rhinoviruses. Clin. Microbiol. Rev. 26, 135-162 (2013)

53. S.K.P. Lau et al., Clinical features and complete genome characterization of a distinct human rhinovirus (HRV) genetic cluster, probably representing a previously undetected HRV species, HRV-C, associated with acute respiratory illness in children. J. Clin. Microbiol. 45, 3655 LP-3653664 (2007)

54. Wang, W. et al. Molecular genotyping of human rhinovirus by using PCR and Sanger sequencing. in 39-47 (2015). https://doi. org/10.1007/978-1-4939-1571-2_4.

55. Greenberg, S. B. Respiratory viral infections: update on human rhinovirus and coronavirus infections. in Seminars in respiratory and critical care medicine vol. 37555 (Thieme Medical Publishers, 2016)

56. J. Jubrail et al., Arpin is critical for phagocytosis in macrophages and is targeted by human rhinovirus. EMBO Rep. 21, e47963 (2020)

57. Falsey, A. R. \& Branche, A. R. Rhinoviruses. in International Encyclopedia of Public Health 363-369 (Elsevier, 2017). https:// doi.org/10.1016/B978-0-12-803678-5.00386-6. 
58. S.B. Greenberg, Update on human rhinovirus and coronavirus infections. Semin Resp Crit Care Med 37, 555-571 (2016)

59. D.N. Tran et al., Human rhinovirus infections in hospitalized children: clinical, epidemiological and virological features. Epidemiol. Infect. 144, 346-354 (2016)

60. Y. Perk, M. Özdil, Respiratory syncytial virüs infections in neonates and infants. Turkish Archives of Pediatrics/Türk Pediatri Arșivi 53, 63 (2018)

61. E.A.F. Simoes, Respiratory syncytial virus infection. Lancet 354, 847-852 (1999)

62. C. Griffiths, S.J. Drews, D.J. Marchant, Respiratory syncytial virus: infection, detection, and new options for prevention and treatment. Clin. Microbiol. Rev. 30, 277-319 (2017)

63. WHO. WHO strategy to pilot global respiratory syncytial virus surveillance based on the Global Influenza Surveillance and Response System (GISRS). https://apps.who.int/iris/handle/ 10665/259853 (2017).

64. B. Ackerson et al., Severe morbidity and mortality associated with respiratory syncytial virus versus influenza infection in hospitalized older adults. Clin. Infect. Dis. 69, 197-203 (2019)

65. Jha, D. A., Jarvis, H., Fraser, C. \& Openshaw, P. J. M. Respiratory syncytial virus. (European Respiratory Society, 2016).

66. H.F. Tseng et al., Severe morbidity and short-and mid-to longterm mortality in older adults hospitalized with respiratory syncytial virus infection. J. Infect. Dis. 222, 1298-1310 (2020)

67. P.L. Collins, B.S. Graham, Viral and host factors in human respiratory syncytial virus pathogenesis. J. Virol. 82, 2040-2055 (2008)

68. K.H. Chan, J.S.M. Peiris, W. Lim, J.M. Nicholls, S.S. Chiu, Comparison of nasopharyngeal flocked swabs and aspirates for rapid diagnosis of respiratory viruses in children. J. Clin. Virol. 42, 65-69 (2008)

69. P. Macfarlane, J. Denham, J. Assous, C. Hughes, RSV testing in bronchiolitis: which nasal sampling method is best? Arch. Dis. Child. 90, 634-635 (2005)

70. D. Higgins, C. Trujillo, C. Keech, Advances in RSV vaccine research and development-A global agenda. Vaccine 34, 2870 2875 (2016)

71. A.R. Branche, A.R. Falsey, Parainfluenza virus infection. Semin Resp Crit Care Med 37, 538-554 (2016)

72. Boncristiani, H. F., Criado, M. F. \& Arruda, E. Respiratory viruses. in Encyclopedia of Microbiology 500-518 (Elsevier, 2009). https://doi.org/10.1016/B978-012373944-5.00314-X.

73. M.Y. Liu et al., Characterization of enterovirus 71 infection and associated outbreak of hand, foot, and mouth disease in Shawo of China in 2012. Sci. Rep. 6, 1-10 (2016)

74. L. Shi et al., Development of SPR biosensor for simultaneous detection of multiplex respiratory viruses. Biomed. Mater. Eng. 26, S2207-S2216 (2015)

75. B.R. O'Keefe et al., Broad-spectrum in vitro activity and in vivo efficacy of the antiviral protein griffithsin against emerging viruses of the family Coronaviridae. J. Virol. 84, 2511-2521 (2010)

76. A.R. Sahin, 2019 Novel coronavirus (COVID-19) outbreak: a review of the current literature. Euras J Med Oncol 4, 1-7 (2020)

77. NIH. COVID-19, MERS \& SARS. https://www.niaid.nih.gov/ diseases-conditions/covid-19.

78. Coronavirus disease (COVID-19) outbreak situation. World Health Organization (2020).

79. M. Ji et al., Automated multiplex nucleic acid tests for rapid detection of SARS-CoV-2, influenza A and B infection with direct reverse-transcription quantitative PCR (dirRT-qPCR) assay in a centrifugal microfluidic platform. RSC Adv. 10, 34088-34098 (2020)

80. Y.-W. Tang, J.E. Schmitz, D.H. Persing, C.W. Stratton, Laboratory diagnosis of COVID-19: current issues and challenges. J. Clin. Microbiol. 58 (2020)
81. Mullis, K. et al. Specific enzymatic amplification of DNA in vitro: the polymerase chain reaction. in Cold Spring Harbor symposia on quantitative biology vol. 51 263-273 (Cold Spring Harbor Laboratory Press, 1986).

82. M.T. Rahman, M.S. Uddin, R. Sultana, A. Moue, M. Setu, Polymerase chain reaction (PCR): a short review. Anwer Khan Mod. Med. Coll. J. 4, 30-36 (2013)

83. K.J. Shaw et al., Rapid PCR amplification using a microfluidic device with integrated microwave heating and air impingement cooling. Lab Chip 10, 1725-1728 (2010)

84. N.W. Schaad, R.D. Frederick, Real-time PCR and its application for rapid plant disease diagnostics. Can. J. Plant Pathol. 24, 250 258 (2002)

85. S.A. Bustin, Absolute quantification of mRNA using real-time reverse transcription polymerase chain reaction assays. J. Mol. Endocrinol. 25, 169-193 (2000)

86. J.S. Chamberlain, R.A. Gibbs, J.E. Rainer, P.N. Nguyen, C. Thomas, Deletion screening of the Duchenne muscular dystrophy locus via multiplex DNA amplification. Nucleic Acids Res. 16, 11141-11156 (1988)

87. M. Echavarria, M. Forman, J. Ticehurst, J.S. Dumler, P. Charache, PCR method for detection of adenovirus in urine of healthy and human immunodeficiency virus-infected individuals. J. Clin. Microbiol. 36, 3323-3326 (1998)

88. W. Xu, M.C. McDonough, D.D. Erdman, Species-specific identification of human adenoviruses by a multiplex PCR assay. J. Clin. Microbiol. 38, 4114-4120 (2000)

89. Z. Gu, S.W. Belzer, C.S. Gibson, M.J. Bankowski, R.T. Hayden, Multiplexed, real-time PCR for quantitative detection of human adenovirus. J. Clin. Microbiol. 41, 4636-4641 (2003)

90. A. Heim, C. Ebnet, G. Harste, P. Pring-Åkerblom, Rapid and quantitative detection of human adenovirus DNA by real-time PCR. J. Med. Virol. 70, 228-239 (2003)

91. K. Ebner, M. Suda, F. Watzinger, T. Lion, Molecular detection and quantitative analysis of the entire spectrum of human adenoviruses by a two-reaction real-time PCR assay. J. Clin. Microbiol. 43, 3049-3053 (2005)

92. M. Damen et al., Real-time PCR with an internal control for detection of all known human adenovirus serotypes. J. Clin. Microbiol. 46, 3997-4003 (2008)

93. G. Dong et al., Development and evaluation of a droplet digital PCR assay for the detection of fowl adenovirus serotypes 4 and 10 in attenuated vaccines. J. Virol. Methods 265, 59-65 (2019)

94. N. Nebeluk, T.P. Foster, Design, validation and evaluation of a SYBR green-based quantitative PCR array for comprehensive analysis of adenovirus type 5 transcriptional patterns. J. Virol. Methods 281, 113880 (2020)

95. J. Ye et al., Primer-BLAST: a tool to design target-specific primers for polymerase chain reaction. BMC bioinformatics 13, 134 (2012)

96. X. Lu et al., Real-time PCR assays for detection of bocavirus in human specimens. J. Clin. Microbiol. 44, 3231 LP-3233235 (2006)

97. F. Neske et al., Real-time PCR for diagnosis of human bocavirus infections and phylogenetic analysis. J. Clin. Microbiol. 45, 2116 2122 (2007)

98. J.-H. Choi et al., Development of real-time PCR assays for detection and quantification of human bocavirus. J. Clin. Virol. 42, 249-253 (2008)

99. K.E. Templeton, S.A. Scheltinga, M.F.C. Beersma, A.C.M. Kroes, E.C.J. Claas, Rapid and sensitive method using multiplex real-time PCR for diagnosis of infections by influenza A and influenza $B$ viruses, respiratory syncytial virus, and parainfluenza viruses 1, 2, 3, and 4. J. Clin. Microbiol. 42, 1564-1569 (2004) 
100. E.C.J. Claas et al., Type-specific identification of influenza viruses $\mathrm{A}, \mathrm{B}$ and $\mathrm{C}$ by the polymerase chain reaction. J. Virol. Methods 39, 1-13 (1992)

101. D. Henritzi et al., A newly developed tetraplex real-time RT-PCR for simultaneous screening of influenza virus types A, B, C and D. Influenza Other Respir. Viruses 13, 71-82 (2019)

102. R. Mentel, U. Wegner, R. Bruns, L. Gürtler, Real-time PCR to improve the diagnosis of respiratory syncytial virus infection. J. Med. Microbiol. 52, 893-896 (2003)

103. L.A.H. Do et al., A sensitive real-time PCR for detection and subgrouping of human respiratory syncytial virus. J. Virol. Methods 179, 250-255 (2012)

104. A.C. Andeweg, T.M. Bestebroer, M. Huybreghs, T.G. Kimman, J.C. de Jong, Improved detection of rhinoviruses in clinical samples by using a newly developed nested reverse transcription-PCR assay. J. Clin. Microbiol. 37, 524 LP-524530 (1999)

105. D.H. Do et al., A One-step, real-time PCR assay for rapid detection of rhinovirus. J Mol Diagn 12, 102-108 (2010)

106. E.L. Tan et al., Rapid detection of Enterovirus 71 by real-time TaqMan RT-PCR. J. Clin. Virol. 42, 203-206 (2008)

107. D. Adachi et al., Comprehensive detection and identification of human coronaviruses, including the SARS-associated coronavirus, with a single RT-PCR assay. J. Virol. Methods 122, 29-36 (2004)

108. S.L. Emery et al., Real-time reverse transcription-polymerase chain reaction assay for SARS-associated coronavirus. Emerg. Infect. Dis. 10, 311 (2004)

109. Q. Wu et al., Development of Taqman RT-nested PCR system for clinical SARS-CoV detection. J. Virol. Methods 119, 17-23 (2004)

110. V.M. Corman et al., Detection of a novel human coronavirus by real-time reverse-transcription polymerase chain reaction. Eurosurveillance 17, 20285 (2012)

111. X. Lu et al., Real-time reverse transcription-PCR assay panel for Middle East respiratory syndrome coronavirus. J. Clin. Microbiol. 52, 67-75 (2014)

112. X. Lu et al., US CDC real-time reverse transcription PCR panel for detection of severe acute respiratory syndrome coronavirus 2 . Emerg. Infect. Dis. 26, 1654 (2020)

113. J.F.-W. Chan et al., Improved molecular diagnosis of COVID-19 by the novel, highly sensitive and specific COVID-19-RdRp/Hel real-time reverse transcription-PCR Assay validated <em $>$ In Vitro $<$ em $>$ and with clinical specimens. J. Clin. Microbiol. 58, e00310-e00320 (2020)

114. R.K. Saiki et al., Primer-directed enzymatic amplification of DNA with a thermostable DNA polymerase. Science 239, 487-491 (1988)

115. T. Notomi et al., Loop-mediated isothermal amplification of DNA. Nucleic Acids Res. 28, e63-e63 (2000)

116. Y. Mori, T. Notomi, Loop-mediated isothermal amplification (LAMP): a rapid, accurate, and cost-effective diagnostic method for infectious diseases. J. Infect. Chemother. 15, 62-69 (2009)

117. R. Abdul-Ghani, A.M. Al-Mekhlafi, P. Karanis, Loop-mediated isothermal amplification (LAMP) for malarial parasites of humans: would it come to clinical reality as a point-of-care test? Acta Trop. 122, 233-240 (2012)

118. Drapala, D. \& Kordalewska, M. Loop-mediated isothermal amplification (LAMP) as a diagnostic tool in detection of infectious diseases. PhD Interdisciplanary Journal 19-23 (2013).

119. T. Wakabayashi, R. Yamashita, T. Kakita, M. Kakita, T. Oshika, Rapid and sensitive diagnosis of adenoviral keratoconjunctivitis by loop-mediated isothermal amplification (LAMP) method. Curr. Eye Res. 29, 219-224 (2004)

120. Y. Sun et al., Four DNA extraction methods used in loop-mediated isothermal amplification for rapid adenovirus detection. J. Virol. Methods 204, 49-52 (2014)
121. M. Ito, M. Watanabe, N. Nakagawa, T. Ihara, Y. Okuno, Rapid detection and typing of influenza $\mathrm{A}$ and $\mathrm{B}$ by loop-mediated isothermal amplification: comparison with immunochromatography and virus isolation. J. Virol. Methods 135, 272-275 (2006)

122. M. Nakauchi et al., Development of real-time fluorescent reverse transcription loop-mediated isothermal amplification assays for rhinovirus detection. J. Med. Virol. 91, 1232-1238 (2019)

123. J. Mahony et al., Development of a sensitive loop-mediated isothermal amplification assay that provides specimen-to-result diagnosis of respiratory syncytial virus infection in 30 minutes. J. Clin. Microbiol. 51, 2696-2701 (2013)

124. Y. Mu et al., New method for the visual detection of human respiratory syncytial virus using reverse transcription loop-mediated amplification. J. Virol. Methods 206, 84-88 (2014)

125. Y. Hu et al., A quite sensitive fluorescent loop-mediated isothermal amplification for rapid detection of respiratory syncytial virus. J. Infect. Dev. Ctries. 13 (2019)

126. X. Wang et al., Detection of enterovirus 71 using reverse transcription loop-mediated isothermal amplification (RT-LAMP). J. Virol. Methods 179, 330-334 (2012)

127. H. Yaqing et al., Detection of human Enterovirus 71 reverse transcription loop-mediated isothermal amplification (RT-LAMP). Lett. Appl. Microbiol. 54, 233-239 (2012)

128. H.T.C. Thai et al., Development and evaluation of a novel loopmediated isothermal amplification method for rapid detection of severe acute respiratory syndrome coronavirus. J. Clin. Microbiol. 42, 1956 LP-1951961 (2004)

129. S.H. Lee et al., One-pot reverse transcriptional loop-mediated isothermal amplification (RT-LAMP) for detecting MERS-CoV. Front. Microbiol. 7 (2017)

130. S. Bhadra et al., Real-time sequence-validated loop-mediated isothermal amplification assays for detection of Middle East respiratory syndrome coronavirus (MERS-CoV). PLoS One 10, e0123126 (2015)

131. P. Huang et al., A rapid and specific assay for the detection of MERS-CoV. Front. Microbiol. 9 (2018)

132. W.E. Huang et al., RT-LAMP for rapid diagnosis of coronavirus SARS-CoV-2. Microb. Biotechnol. 13, 950-961 (2020)

133. G.-S. Park et al., Development of reverse transcription loopmediated isothermal amplification assays targeting severe acute respiratory syndrome coronavirus 2 (SARS-CoV-2). J Mol Diagn 22, 729-735 (2020)

134. X. Hu et al., Development and clinical application of a rapid and sensitive loop-mediated isothermal amplification test for SARSCoV-2 infection. mSphere 5, e00808-e00820 (2020)

135. M. Schena, D. Shalon, R.W. Davis, P.O. Brown, Quantitative monitoring of gene expression patterns with a complementary DNA microarray. Science 270, 467-470 (1995)

136. A. Singh, N. Kumar, A review on DNA microarray technology. Int. J. Curr. Res Rev 5, 1 (2013)

137. A.J. Gawron, R.S. Martin, S.M. Lunte, Microchip electrophoretic separation systems for biomedical and pharmaceutical analysis. Eur. J. Pharm. Sci. 14, 1-12 (2001)

138. C.A. Afshari, Perspective: microarray technology, seeing more than spots. Endocrinology 143, 1983-1989 (2002)

139. J.W. Gray, C. Collins, Genome changes and gene expression in human solid tumors. Carcinogenesis 21, 443-452 (2000)

140. M. Kaur, S. Tiwari, R. Jain, Protein based biomarkers for noninvasive Covid-19 detection. Sens Biosensing Res 29, 100362 (2020)

141. M. Natesan, R.G. Ulrich, Protein microarrays and biomarkers of infectious disease. Int. J. Mol. Sci. 11, 5165-5183 (2010)

142. F.X.R. Sutandy, J. Qian, C. Chen, H. Zhu, Overview of protein microarrays. Curr Protoc Protein Sci 72, 21-27 (2013) 
143. R. Nakajima et al., Protein microarray analysis of the specificity and cross-reactivity of influenza virus hemagglutinin-specific antibodies. MSphere 3 (2018)

144. M.A. Plotnikova et al., Antibody microarray immunoassay for screening and differential diagnosis of upper respiratory tract viral pathogens. J. Immunol. Methods 478, 112712 (2020)

145. S.-R. Shih et al., Serotype-specific detection of enterovirus 71 in clinical specimens by DNA microchip array. J. Virol. Methods 111, 55-60 (2003)

146. P.-L. Quan et al., Detection of respiratory viruses and subtype identification of influenza A viruses by GreeneChipResp oligonucleotide microarray. J. Clin. Microbiol. 45, 2359-2364 (2007)

147. G. López-Campos et al., Oligonucleotide microarray design for detection and serotyping of human respiratory adenoviruses by using a virtual amplicon retrieval software. J. Virol. Methods 145, 127-136 (2007)

148. S. Nybond et al., Adenoviral detection by recombinase polymerase amplification and vertical flow paper microarray. Anal. Bioanal. Chem. 411, 813-822 (2019)

149. W.-H. Long et al., A universal microarray for detection of SARS coronavirus. J. Virol. Methods 121, 57-63 (2004)

150. X. Guo, P. Geng, Q. Wang, B. Cao, B. Liu, Development of a single nucleotide polymorphism DNA microarray for the detection and genotyping of the SARS coronavirus. J. Microbiol. Biotechnol. 24, 1445-1454 (2014)

151. R.M. Lequin, Enzyme immunoassay (EIA)/enzyme-linked immunosorbent assay (ELISA). Clin. Chem. 51, 2415-2418 (2005)

152. S. Avranmeas, J. Uriel, Methode de marquage d'antigènes et d'anticorpes avec des enzymes son application en immunodiffusions. CR Acad Sci 262, 2540-2543 (1966)

153. S. Avrameas, Coupling of enzymes to proteins with glutaraldehyde: use of the conjugates for the detection of antigens and antibodies. Immunochemistry 6, 43-52 (1969)

154. B. Van Weemen, A. Schuurs, Immunoassay using antigenenzyme conjugates. FEBS Lett. 15, 232-236 (1971)

155. Crowther, J. R. Systems in ELISA. in ELISA Guidebook, The (ed. Crowther, J. R.) 9-44 (Humana Press, 2000). doi:10.1385/159259-049-7:9.

156. M.W. Harmon, S. Drake, J.A. Kasel, Detection of adenovirus by enzyme-linked immunosorbent assay. J. Clin. Microbiol. 9, 342346 (1979)

157. W. Al-Nakib, C.J. Dearden, D.A.J. Tyrrell, Evaluation of a new enzyme-linked immunosorbent assay (ELISA) in the diagnosis of rhinovirus infection. J. Med. Virol. 29, 268-272 (1989)

158. L. Zhan, W.B. Wu, X.X. Yang, C.Z. Huang, Gold nanoparticlebased enhanced ELISA for respiratory syncytial virus. New J. Chem. 38, 2935-2940 (2014)

159. K. Leirs et al., Bioassay development for ultrasensitive detection of influenza A nucleoprotein using digital ELISA. Anal. Chem. 88, 8450-8458 (2016)

160. S.K.P. Lau et al., Detection of severe acute respiratory syndrome (SARS) coronavirus nucleocapsid protein in SARS patients by enzyme-linked immunosorbent assay. J. Clin. Microbiol. 42, 2884 LP-2882889 (2004)

161. L. Schöler et al., A Novel in-cell ELISA assay allows rapid and automated quantification of SARS-CoV-2 to analyze neutralizing antibodies and antiviral compounds. Front. Immunol. 11, 2673 (2020)

162. S.M. Nimjee, R.R. White, R.C. Becker, B.A. Sullenger, Aptamers as therapeutics. Annu. Rev. Pharmacol. Toxicol. 57, 61-79 (2017)

163. Gopinath, S. C. B. Aptamers. in Encyclopedia of Analytical Chemistry 1-33 (John Wiley \& Sons, Ltd, 2016). https://doi.org/ 10.1002/9780470027318.a1402.pub3.

164. C. Cheng et al., Potent inhibition of human influenza H5N1 virus by oligonucleotides derived by SELEX. Biochem. Biophys. Res. Commun. 366, 670-674 (2008)
165. R. Wang et al., Selection and characterization of DNA aptamers for use in detection of avian influenza virus H5N1. J. Virol. Methods 189, 362-369 (2013)

166. I. Shiratori et al., Selection of DNA aptamers that bind to influenza A viruses with high affinity and broad subtype specificity. Biochem. Biophys. Res. Commun. 443, 37-41 (2014)

167. S.C.B. Gopinath, Y. Sakamaki, K. Kawasaki, P.K.R. Kumar, An efficient RNA aptamer against human influenza B virus hemagglutinin. J. Biochem 139, 837-846 (2006)

168. H.-C. Lai, C.-H. Wang, T.-M. Liou, G.-B. Lee, Influenza A virusspecific aptamers screened by using an integrated microfluidic system. Lab Chip 14, 2002-2013 (2014)

169. K. Percze et al., Aptamers for respiratory syncytial virus detection. Sci. Rep. 7, 42794 (2017)

170. L. Zhang et al., Discovery of sandwich type COVID-19 nucleocapsid protein DNA aptamers. Chem. Commun. 56, 10235 $10238(2020)$

171. R. Liu, L. He, Y. Hu, Z. Luo, J. Zhang, A serological aptamerassisted proximity ligation assay for COVID-19 diagnosis and seeking neutralizing aptamers. Chem. Sci. 11, 12157-12164 (2020)

172. J.B. Mahony, Detection of respiratory viruses by molecular methods. Clin. Microbiol. Rev. 21, 716-747 (2008)

173. F. Hu, X. Shang, M. Chen, C. Zhang, Joint detection of serum $\operatorname{IgM} / \operatorname{IgG}$ antibody is an important key to clinical diagnosis of SARS-CoV-2 infection. Can. J. Infect. Dis. Med. Microbiol. 2020, 1-5 (2020)

174. H. Hou et al., Detection of $\operatorname{IgM}$ and $\operatorname{IgG}$ antibodies in patients with coronavirus disease 2019. Clin. Transl. Immunol. 9 (2020)

175. J. Van Elslande et al., Diagnostic performance of seven rapid IgG/ $\operatorname{IgM}$ antibody tests and the Euroimmun $\operatorname{IgA} / \operatorname{IgG}$ ELISA in COVID-19 patients. Clin. Microbiol. Infect. 26, 1082-1087 (2020)

176. T. Vuorinen, O. Meurman, Enzyme immunoassays for detection of IgG and IgM antibodies to parainfluenza types 1, 2 and 3. J. Virol. Methods 23, 63-70 (1989)

177. M. Roggendorf, R. Wigand, F. Deinhardt, G.G. Frösner, Enzymelinked immunosorbent assay for acute adenovirus infection. J. Virol. Methods 4, 27-35 (1982)

178. W.S. Barclay, W. Al-Nakib, An ELISA for the detection of rhinovirus specific antibody in serum and nasal secretion. J. Virol. Methods 15, 53-64 (1987)

179. S.-Y. Wang, T.-L. Lin, H.-Y. Chen, T.-S. Lin, Early and rapid detection of enterovirus 71 infection by an IgM-capture ELISA. J. Virol. Methods 119, 37-43 (2004)

180. M.A. MacMullan et al., ELISA detection of SARS-CoV-2 antibodies in saliva. Sci. Rep. 10, 20818 (2020)

181. V. Gubala, L.F. Harris, A.J. Ricco, M.X. Tan, D.E. Williams, Point of care diagnostics: status and future. Anal. Chem. 84, 487-515 (2012)

182. N. Pires, T. Dong, U. Hanke, N. Hoivik, Recent developments in optical detection technologies in lab-on-a-chip devices for biosensing applications. Sensors 14, 15458-15479 (2014)

183. R. Bharadwaj et al., Evanescent wave absorbance based fiber optic biosensor for label-free detection of E. coli at $280 \mathrm{~nm}$ wavelength. Biosens. Bioelectron. 26, 3367-3370 (2011)

184. Jiao, L. et al. Recent advances in fiber-optic evanescent wave sensors for monitoring organic and inorganic pollutants in water. TrAC Trends in Analytical Chemistry 115892 (2020).

185. M. Elsherif, R. Moreddu, M.U. Hassan, A.K. Yetisen, H. Butt, Real-time optical fiber sensors based on light diffusing microlens arrays. Lab Chip 19, 2060-2070 (2019)

186. Y. Tang et al., Evanescent wave aptasensor for continuous and online aminoglycoside antibiotics detection based on target binding facilitated fluorescence quenching. Biosens. Bioelectron. 102, 646-651 (2018) 
187. P. Nag, K. Sadani, S. Mukherji, Optical fiber sensors for rapid screening of COVID-19. Transactions of the Indian National Academy of Engineering 5, 233-236 (2020)

188. D. Murugan, H. Bhatia, V.V.R. Sai, J. Satija, P-FAB: a fiber-optic biosensor device for rapid detection of COVID-19. Transactions of the Indian National Academy of Engineering 5, 211-215 (2020)

189. J. Moon et al., Surface-independent and oriented immobilization of antibody via one-step polydopamine/protein G coating: application to influenza virus immunoassay. Macromol. Biosci. 19, 1800486 (2019)

190. X. Fang, Y. Liu, J. Kong, X. Jiang, Loop-mediated isothermal amplification integrated on microfluidic chips for point-of-care quantitative detection of pathogens. Anal. Chem. 82, 3002-3006 (2010)

191. H. Ahn, H. Song, J. Choi, K. Kim, A localized surface plasmon resonance sensor using double-metal-complex nanostructures and a review of recent approaches. Sensors 18, 98 (2017)

192. M. Asif et al., The role of biosensors in coronavirus disease-2019 outbreak. Curr Opin Electrochem 23, 174-184 (2020)

193. Y. Chen, H. Ming, Review of surface plasmon resonance and localized surface plasmon resonance sensor? Photonic Sensors 2, 37-49 (2012)

194. Y.F. Chang et al., Simple strategy for rapid and sensitive detection of avian influenza A H7N9 virus based on intensity-modulated SPR biosensor and new generated antibody. Anal. Chem. 90, 1861-1869 (2018)

195. P.P. Nelson et al., Current and future point-of-care tests for emerging and new respiratory viruses and future perspectives. Front. Cell. Infect. Microbiol. 10 (2020)

196. F. Nasrin et al., Single-step detection of norovirus tuning localized surface plasmon resonance-induced optical signal between gold nanoparticles and quantum dots. Biosens. Bioelectron. 122, 1624 (2018)

197. N.S. Heo et al., Affinity peptide-guided plasmonic biosensor for detection of noroviral protein and human norovirus. Biotechnol. Bioprocess Eng. 24, 318-325 (2019)

198. E. Shabani, S. Dowlatshahi, M.J. Abdekhodaie, Laboratory detection methods for the human coronaviruses. Eur. J. Clin. Microbiol. Infect. Dis., 1-22 (2020). https://doi.org/10.1007/s10096-02004001-8

199. C.L. Wong et al., A phase-intensity surface plasmon resonance biosensor for avian influenza A (H5N1) detection. Sensors 17, 2363 (2017)

200. B.A. Prabowo et al., Rapid detection and quantification of Enterovirus 71 by a portable surface plasmon resonance biosensor. Biosens. Bioelectron. 92, 186-191 (2017)

201. G. Qiu et al., Dual-functional plasmonic photothermal biosensors for highly accurate severe acute respiratory syndrome coronavirus 2 detection. ACS Nano 14, 5268-5277 (2020)

202. H. Yoo, J. Shin, J. Sim, H. Cho, S. Hong, Reusable surface plasmon resonance biosensor chip for the detection of H1N1 influenza virus. Biosens. Bioelectron. 168, 112561 (2020)

203. Ramachandran, A. et al. Electric field-driven microfluidics for rapid CRISPR-based diagnostics and its application to detection of SARS-CoV-2. Proceedings of the National Academy of Sciences 117, 29518-29525 (2020).

204. R.-Q. Zhang, S.-L. Hong, C.-Y. Wen, D.-W. Pang, Z.-L. Zhang, Rapid detection and subtyping of multiple influenza viruses on a microfluidic chip integrated with controllable micro-magnetic field. Biosens. Bioelectron. 100, 348-354 (2018)

205. C.-H. Wang, C.-P. Chang, G.-B. Lee, Integrated microfluidic device using a single universal aptamer to detect multiple types of influenza viruses. Biosens. Bioelectron. 86, 247-254 (2016)
206. K.-Y. Lien et al., Rapid detection of influenza A virus infection utilizing an immunomagnetic bead-based microfluidic system. Biosens. Bioelectron. 26, 3900-3907 (2011)

207. Z. Wu et al., Digital single virus immunoassay for ultrasensitive multiplex avian influenza virus detection based on fluorescent magnetic multifunctional nanospheres. ACS Appl. Mater. Interfaces 11, 5762-5770 (2019)

208. E. Vermisoglou et al., Human virus detection with graphene-based materials. Biosens. Bioelectron. 166, 112436 (2020)

209. K.F. Lei et al., Paper-based enzyme-free immunoassay for rapid detection and subtyping of influenza A H1N1 and H3N2 viruses. Anal. Chim. Acta 883, 37-44 (2015)

210. P. Teengam et al., Multiplex paper-based colorimetric DNA sensor using pyrrolidinyl peptide nucleic acid-induced AgNPs aggregation for detecting MERS-CoV, MTB, and HPV oligonucleotides. Anal. Chem. 89, 5428-5435 (2017)

211. J.H. Jung et al., Combination of multiplex reverse-transcription loop-mediated isothermal amplification with an immunochromatographic strip for subtyping influenza A virus. Anal. Chim. Acta 853, 541-547 (2015)

212. Y.-D. Ma et al., A sample-to-answer, portable platform for rapid detection of pathogens with a smartphone interface. Lab Chip 19, 3804-3814 (2019)

213. I.Y. Jung et al., A highly sensitive molecular detection platform for robust and facile diagnosis of Middle East respiratory syndrome (MERS) corona virus. Adv. Healthc. Mater 5, 2168-2173 (2016)

214. C. Wang et al., Magnetic SERS strip for sensitive and simultaneous detection of respiratory viruses. ACS Appl. Mater. Interfaces 11, 19495-19505 (2019)

215. Ahmadivand, A. et al. Femtomolar-level detection of SARS-CoV2 spike proteins using toroidal plasmonic metasensors. arXiv preprint arXiv:2006.08536 (2020).

216. Vu \& Chen. Field-effect transistor biosensors for biomedical applications: recent advances and future prospects. Sensors 19, 4214 (2019).

217. A.K. Kaushik et al., Electrochemical SARS-CoV-2 sensing at point-of-care and artificial intelligence for intelligent COVID-19 management. ACS Appl. Bio Mater. 3, 7306-7325 (2020)

218. A.M. Mohammed et al., Application of gold nanoparticles for electrochemical DNA biosensor. J. Nanomater. 2014(683460) (2014)

219. Y. Al-Douri, K. Gherab, K.M. Batoo, E.H. Raslan, Detecting the DNA of dengue serotype 2 using aluminium nanoparticle doped zinc oxide nanostructure: synthesis, analysis and characterization. J. Mater. Res. Technol 9, 5515-5523 (2020)

220. R. Singh, S. Hong, J. Jang, Label-free detection of influenza viruses using a reduced graphene oxide-based electrochemical immunosensor integrated with a microfluidic platform. Sci. Rep. 7, 42771 (2017)

221. L.T.-H. Kao et al., Multiplexed detection and differentiation of the DNA strains for influenza A (H1N1 2009) using a silicon-based microfluidic system. Biosens. Bioelectron. 26, 2006-2011 (2011)

222. K. Yamanaka et al., Rapid detection for primary screening of influenza A virus: microfluidic RT-PCR chip and electrochemical DNA sensor. Analyst 136, 2064 (2011)

223. E. Nunez-Bajo et al., Ultra-low-cost integrated silicon-based transducer for on-site, genetic detection of pathogens. bioRxiv (2020). https://doi.org/10.1101/2020.03.23.002931

224. P. Chiang et al., Nanowire transistor-based ultrasensitive virus detection with reversible surface functionalization. Chem. Asian J. 7, 2073-2079 (2012)

225. Y. Fu et al., Chemiresistive biosensors based on carbon nanotubes for label-free detection of DNA sequences derived from avian influenza virus H5N1. Sensors Actuators B Chem. 249, 691-699 (2017) 
226. C. Chan, J. Shi, Y. Fan, M. Yang, A microfluidic flow-through chip integrated with reduced graphene oxide transistor for influenza virus gene detection. Sensors Actuators B Chem. 251, 927933 (2017)

227. G. Seo et al., Rapid detection of COVID-19 causative virus (SARS-CoV-2) in human nasopharyngeal swab specimens using field-effect transistor-based biosensor. ACS Nano 14, 5135-5142 (2020)

228. K. Kiilerich-Pedersen, J. Daprà, S. Cherré, N. Rozlosnik, High sensitivity point-of-care device for direct virus diagnostics. Biosens. Bioelectron. 49, 374-379 (2013)

229. J. Bhardwaj, A. Sharma, J. Jang, Vertical flow-based paper immunosensor for rapid electrochemical and colorimetric detection of influenza virus using a different pore size sample pad. Biosens. Bioelectron. 126, 36-43 (2019)

230 J.-H. Han, D. Lee, C.H.C. Chew, T. Kim, J.J. Pak, A multi-virus detectable microfluidic electrochemical immunosensor for simultaneous detection of $\mathrm{H} 1 \mathrm{~N} 1, \mathrm{H} 5 \mathrm{~N} 1$, and $\mathrm{H} 7 \mathrm{~N} 9$ virus using $\mathrm{ZnO}$ nanorods for sensitivity enhancement. Sensors Actuators B Chem. 228, 36-42 (2016)

231. M. Sayhi et al., Electrochemical detection of influenza virus H9N2 based on both immunomagnetic extraction and gold catalysis using an immobilization-free screen printed carbon microelectrode. Biosens. Bioelectron. 107, 170-177 (2018)

232. Mahari, S., Roberts, A., Shahdeo, D. \& Gandhi, S. eCovSensultrasensitive novel in-house built printed circuit board based electrochemical device for rapid detection of nCovid-19 antigen, a spike protein domain 1 of SARS-CoV-2. bioRxiv 2020.04.24.059204 (2020). https://doi.org/10.1101/2020.04.24. 059204 .

233. L. Krejcova et al., 3D printed chip for electrochemical detection of influenza virus labeled with $\mathrm{CdS}$ quantum dots. Biosens. Bioelectron. 54, 421-427 (2014)

234. Y. Jiang et al., SAW sensor for Influenza A virus detection enabled with efficient surface functionalization. Sensors Actuators B Chem. 209, 78-84 (2015)

235. Kagiyama, S., Masuda, T., Kaihatsu, K., Kato, N. \& Arai, F. Detection of influenza virus subtype using quartz crystal microbalance. in 2014 International Symposium on MicroNanoMechatronics and Human Science (MHS) 1-2 (IEEE, 2014). https://doi.org/10.1109/MHS.2014.7006130.

236. A. Moran et al., Detection of SARS-CoV-2 by use of the Cepheid Xpert Xpress SARS-CoV-2 and Roche cobas SARS-CoV-2 Assays. J. Clin. Microbiol. 58 (2020)

237. W. Xing et al., A high-throughput, multi-index isothermal amplification platform for rapid detection of 19 types of common respiratory viruses including SARS-CoV-2. Engineering 6, 1130-1140 (2020)

238. Biomerieux. BIOFIRE® Respiratory 2.1 plus Panel. https:// www.biomerieux-diagnostics.com/filmarrayr-respiratory-panel (2020).

239. Alveo Technologies. No Title. https://www.alveotechnologies.com/ science/ (2020)

240. J. Teo et al., VereFlu ${ }^{\mathrm{TM}}$ : An integrated multiplex RT-PCR and microarray assay for rapid detection and identification of human influenza A and B viruses using lab-on-chip technology. Arch. Virol. (2011). https://doi.org/10.1007/s00705-011-0999-7

241. Veredus. VereCoV (IVD). https://vereduslabs.com/products/ infectiousdiseases/verecov/.

242. Abbott. Alere BinaxNOW® Influenza A\&B Card. https:// www.globalpointofcare.abbott/en/index.html (2020).

243. Abbott. ID NOW ${ }^{\mathrm{TM}}$ Influenza A \& B 2. https:/www.globalpointofare.abbott/ en/product-detailsid-now-influenza-ab-2.html (2020).

244. Abbott. ID NOW ${ }^{\mathrm{TM}}$ RSV. https://www.globalpointofcare.abbott/ en/product-details/id-now-rsv.html (2020).
245. Abbott. ID NOW ${ }^{\mathrm{TM}}$ COVID-19. https://www.globalpointofcare.abbott/ en/product-details/id-now-covid-19-ous.html (2020).

246. F. da Silva Mesquita et al., Rapid antigen detection test for respiratory syncytial virus diagnosis as a diagnostic tool. Jornal de Pediatria (Versão em Português) 93(246-252) (2017)

247. W. Poeppl et al., Performance of the QuickVue Influenza A+ B rapid test for pandemic H1N1 (2009) virus infection in adults. PLoS One 6, e28089 (2011)

248. J.M.S. Velasco et al., Evaluation of QuickVue influenza A+ B rapid test for detection of pandemic influenza A/H1N1 2009. J. Clin. Virol. 48, 120-122 (2010)

249. QuickVue Influenza A+B Test. Quidel https://www.quidel.com/ immunoassays/rapid-influenza-tests/quickvue-influenza-test (2020)

250. Quidel. QuickVue RSV Test. https://www.quidel.com/immunoassays/rapid-rsv-tests/quickvue-rsv-test (2020).

251. K. Agoritsas et al., Evaluation of the Quidel QuickVue test for detection of influenza A and B viruses in the pediatric emergency medicine setting by use of three specimen collection methods. J. Clin. Microbiol. 44, 2638-2641 (2006)

252. FDA. In vitro diagnostics EUAs. U. S. Food and Drug Administration https://www.fda.gov/medical-devices/coronavirus-disease-2019-covid-19-emergency-use-authorizations-medical-devices/vitro-diagnostics-euas (2020).

253. R. Mazetyte-Stasinskiene, J.M. Köhler, Sensor micro and nanoparticles for microfluidic application. Appl. Sci. 10, 8353 (2020)

254. G.W. Hunter et al., Editors' choice - critical review - a critical review of solid state gas sensors. J. Electrochem. Soc. 167, $037570(2020)$

255. E.T. Martin, J. Kuypers, A. Wald, J.A. Englund, Multiple versus single virus respiratory infections: viral load and clinical disease severity in hospitalized children. Influenza Other Respir. Viruses 6, 71-77 (2012)

256. V. Miralles, A. Huerre, F. Malloggi, M.-C. Jullien, A review of heating and temperature control in microfluidic systems: techniques and applications. Diagnostics 3, 33-67 (2013)

257. K.W. Oh, K. Lee, B. Ahn, E.P. Furlani, Design of pressure-driven microfluidic networks using electric circuit analogy. Lab Chip 12, 515-545 (2012)

258. F. Tian et al., A fully automated centrifugal microfluidic system for sample-to-answer viral nucleic acid testing. SCIENCE CHINA Chem. 63, 1498-1506 (2020)

259. Tarim, E. A., Karakuzu, B., Ozcivici, E. \& Tekin, H. C. Active mixing strategy with electromechanical platform for lab-on-a-chip applications. in 2019 Innovations in Intelligent Systems and Applications Conference (ASYU) 1-4 (IEEE, 2019). https://doi. org/10.1109/ASYU48272.2019.8946328.

260. H. Maruyama et al., Nanomanipulation of single influenza virus using dielectrophoretic concentration and optical tweezers for single virus infection to a specific cell on a microfluidic chip. Microfluid. Nanofluid. 10, 1109-1117 (2011)

261. S.S. Ba Hashwan, M.H.B.M. Khir, Y. Al-Douri, A.Y. Ahmed, Recent progress in the development of biosensors for chemicals and pesticides detection. IEEE Access (2020). https://doi.org/10. 1109/ACCESS.2020.2991380

262. M. Waris et al., Comparison of sampling methods for the detection of human rhinovirus RNA. J. Clin. Virol. 58, 200-204 (2013)

263. N. Güemes-Villahoz et al., Detecting SARS-CoV-2 RNA in conjunctival secretions: Is it a valuable diagnostic method of COVID19? J. Med. Virol. 93, 383-388 (2021)

264. K.H. Hong et al., Guidelines for laboratory diagnosis of coronavirus disease 2019 (COVID-19) in Korea. Ann Lab Med 40, 351$360(2020)$

265. Y. Huang et al., SARS-CoV-2 Viral load in clinical samples from critically ill patients. Am. J. Respir. Crit. Care Med. 201, 1435$1438(2020)$ 
266. S. Spencer, M.G. Thompson, B. Flannery, A. Fry, Comparison of respiratory specimen collection methods for detection of influenza virus infection by reverse transcription-PCR: a literature review. J. Clin. Microbiol. 57, e00027-e00019 (2019)

267. Y. Yang et al., Laboratory diagnosis and monitoring the viral shedding of SARS-CoV-2 Infection. The Innovation 1, 100061 (2020)

268. H. Yun et al., Laboratory data analysis of novel coronavirus (COVID-19) screening in 2510 patients. Clin. Chim. Acta (2020)

269. L. Gorgannezhad, H. Stratton, N.-T. Nguyen, Microfluidic-based nucleic acid amplification systems in microbiology. Micromachines 10, 408 (2019)

270. N. Ali, Rampazzo, R. de C. P., Costa, A. D. T. \& Krieger, M. A. Current nucleic acid extraction methods and their implications to point-of-care diagnostics. Biomed. Res. Int. 2017, 1-13 (2017)

271. M.D. Escobar, J.L. Hunt, A cost-effective RNA extraction technique from animal cells and tissue using silica columns. J. Biol. Methods 4, 72 (2017)

272. A. Amiri, F. Firoozeh, M. Zibaei, I. Salahshoorifar, Comparative study of extracted nucleic acid from Escherichia coli by two methods phenol-chloroform and extraction using magnetic nanoparticle. Alborz University Medical Journal 9, 235-240 (2020)

273. S.A. Thatcher, DNA/RNA preparation for molecular detection. Clin. Chem. 61, 89-99 (2015)

274. E.A. Oblath, W.H. Henley, J.P. Alarie, J.M. Ramsey, A microfluidic chip integrating DNA extraction and real-time PCR for the detection of bacteria in saliva. Lab Chip 13, 1325-1332 (2013)

275. D. Nargessi, C.-Y. Ou, MagaZorb: a simple tool for rapid isolation of viral nucleic acids. J. Infect. Dis. 201, S37-S41 (2010)

276. H. He et al., Integrated DNA and RNA extraction using magnetic beads from viral pathogens causing acute respiratory infections. Sci. Rep. 7, 45199 (2017)

277. V.K. Rajendran, P. Bakthavathsalam, P.L. Bergquist, A. Sunna, A portable nucleic acid detection system using natural convection combined with a smartphone. Biosens. Bioelectron. 134, 68-75 (2019)

278. J.R. Choi et al., Paper-based sample-to-answer molecular diagnostic platform for point-of-care diagnostics. Biosens. Bioelectron. 74, 427-439 (2015)

279. Y. Zou et al., Nucleic acid purification from plants, animals and microbes in under 30 seconds. PLoS Biol. 15, e2003916 (2017)

280. Loens, K. \& Ieven, M. Using nucleic acid amplification techniques in a syndrome-oriented approach: detection of respiratory agents. in Molecular Microbiology 306-335 (American Society of Microbiology, 2016). https://doi.org/10.1128/9781555819071. ch25.

281. M. Kabir, Molecular methods for detection of pathogenic viruses of respiratory tract\&\#8212; A review. Asian Pac. J. Trop. Biomed. 8, 237-244 (2018)

282. H. Qi, S. Yue, S. Bi, C. Ding, W. Song, Isothermal exponential amplification techniques: from basic principles to applications in electrochemical biosensors. Biosens. Bioelectron. 110, 207-217 (2018)

283. L. Magro et al., Paper microfluidics for nucleic acid amplification testing (NAAT) of infectious diseases. Lab Chip 17, 2347-2371 (2017)

284. R.K. Daher, G. Stewart, M. Boissinot, M.G. Bergeron, Recombinase polymerase amplification for diagnostic applications. Clin. Chem. (2016). https://doi.org/10.1373/clinchem. 2015.245829
285. Biolabs, N. E. Helicase-dependent amplification. https:// international.neb.com/applications/dna-amplification-pcr-andqpcr/isothermal-amplification/helicase-dependent-amplification.

286. W. Zhang et al., Ligase chain reaction-based electrochemical biosensor for the ultrasensitive and specific detection of single nucleotide polymorphisms. New J. Chem. 43, 14327-14335 (2019)

287. L.M. Zanoli, G. Spoto, Isothermal amplification methods for the detection of nucleic acids in microfluidic devices. Biosensors $\mathbf{3}$, 18-43 (2013)

288. F. Ahmad, S.A. Hashsham, Miniaturized nucleic acid amplification systems for rapid and point-of-care diagnostics: a review. Anal. Chim. Acta 733, 1-15 (2012)

289. J.M. Campbell et al., Microfluidic and paper-based devices for disease detection and diagnostic research. Int. J. Mol. Sci. (2018). https://doi.org/10.3390/ijms19092731

290. J.I.A. Rashid, N.A. Yusof, The strategies of DNA immobilization and hybridization detection mechanism in the construction of electrochemical DNA sensor: a review. Sens Biosensing Res (2017). https://doi.org/10.1016/j.sbsr.2017.09.001

291. J. Kongpeth, S. Jampasa, P. Chaumpluk, O. Chailapakul, T. Vilaivan, Immobilization-free electrochemical DNA detection with anthraquinone-labeled pyrrolidinyl peptide nucleic acid probe. Talanta (2016). https://doi.org/10.1016/j.talanta.2015.08. 059

292. S. Nimse, K. Song, M. Sonawane, D. Sayyed, T. Kim, Immobilization techniques for microarray: challenges and applications. Sensors 14, 22208-22229 (2014)

293. J. Wu, M. Gu, Microfluidic sensing: state of the art fabrication and detection techniques. J. Biomed. Opt. (2011). https://doi.org/10. $1117 / 1.3607430$

294. D. Kim, A.E. Herr, Protein immobilization techniques for microfluidic assays. Biomicrofluidics (2013). https://doi.org/10. 1063/1.4816934

295. M.P. Wolf, G.B. Salieb-Beugelaar, P. Hunziker, PDMS with designer functionalities - properties, modifications strategies, and applications. Prog. Polym. Sci. (2018). https://doi.org/10.1016/j. progpolymsci.2018.06.001

296. R. Kizek et al., Nanoscale virus biosensors: state of the art. Nanobiosensors in Disease Diagnosis (2015). https://doi.org/10. 2147/ndd.s56771

297. A.S. Ibraheam, Y. Al-Douri, S.C.B. Gopinath, U. Hashim, A novel quinternary alloy $(\mathrm{Cu} 2 \mathrm{Zn} 1-\mathrm{xCdxSnS4})$ nanostructured sensor for biomedical diagnosis. Mater. Res. Express 3, 85022 (2016)

298. A.A. Odeh et al., A needle-like Cu2CdSnS4 alloy nanostructurebased integrated electrochemical biosensor for detecting the DNA of Dengue serotype 2. Microchim. Acta 184, 2211-2218 (2017)

299. M.R. Benzigar, R. Bhattacharjee, M. Baharfar, G. Liu, Current methods for diagnosis of human coronaviruses: pros and cons. Anal. Bioanal. Chem. (2020). https://doi.org/10.1007/s00216020-03046-0

300. Gorgens Marelize, S. Z. Purpose and Options for Testing for SARS-Cov2 (the COVID-19 virus): Considerations for World Bank Task Teams Managing COVID-19 Fast Track Facility Operations. (2020).

301. K.F. Sonnen, C.A. Merten, Microfluidics as an emerging precision tool in developmental biology. Dev. Cell 48, 293-311 (2019)

302. D.T. Chiu et al., Small but perfectly formed? Successes, challenges, and opportunities for microfluidics in the chemical and biological sciences. Chem 2, 201-223 (2017) 